\title{
Anxiety in Children and Adolescents with Autism Spectrum Disorders
}

\author{
Susan W. White ${ }^{\mathrm{a}}$, Donald Oswald ${ }^{\mathrm{b}}$, Thomas Ollendick ${ }^{\mathrm{a}}$, and Lawrence Scahill ${ }^{\mathrm{C}}$ \\ aVirginia Polytechnic Institute and State University, Department of Psychology, 109 Williams Hall (0436), \\ Blacksburg,VA24061,sww@vt.edu,tho@vt.edu \\ bVirginia Treatment Center for Children, Virginia Commonwealth University, 515 North $10^{\text {th }}$ Street, PO Box \\ 980489, Richmond,VA 23298-0489, doswald@vcu.edu
}

cYale Child Study Center, Yale University, 230 South Frontage Street, New Haven, CT 06520, lawrence.scahill@yale.edu

\section{Abstract}

Anxiety and poor stress management are common concerns in clinical samples of children with autism spectrum disorders (ASD). Anxiety may worsen during adolescence, as young people face an increasingly complex social milieu and often become more aware of their differences and interpersonal difficulties. This review summarizes the state of research on the prevalence, phenomenology, and treatment of anxiety in youth with autism and related conditions such as Asperger's disorder. Using search words autism, asperger(s), or pervasive developmental disorder and anxiety or anxious to find reports published between 1990 and 2008, this review identified 40 papers. The results of the review suggest that anxiety, whether measured categorically or dimensionally, is indeed common in children and adolescents with autism spectrum disorders and may be a source of additional morbidity. The assessment of anxiety disorders in ASD should be conducted using multiple informants and modalities, as children with ASD often do not display agetypical symptoms of anxiety. To date, relatively few controlled intervention studies using wellcharacterized samples have been conducted despite preliminary evidence for efficacy of select pharmacological and psychosocial approaches. Recommendations for future applied research are presented and clinical implications are explored.

\section{Keywords}

Autism; Asperger's Disorder; anxiety

\begin{abstract}
Autism spectrum disorders (ASD) are characterized by deficits in social interaction and communication, as well as the presence of stereotyped behavior and restricted interests (American Psychiatric Association, Diagnostic and Statistical Manual of Mental Disorders $4^{\text {th }}$ Ed. -Text Revision, 2000). Once regarded as rare, this group of disorders - which includes Autistic Disorder, Asperger's Disorder, and Pervasive Developmental Disorder-Not Otherwise Specified (PDD-NOS), has received a great deal of professional and scientific attention. Based on recent survey findings, the United States Centers for Disease Control (2007) reported that
\end{abstract}

Corresponding author: Susan W. White, Ph.D., Tel. (540)231-6174, Fax. (540)231-3652, E-mail: sww@ vt.edu.

Publisher's Disclaimer: This is a PDF file of an unedited manuscript that has been accepted for publication. As a service to our customers we are providing this early version of the manuscript. The manuscript will undergo copyediting, typesetting, and review of the resulting proof before it is published in its final citable form. Please note that during the production process errors may be discovered which could affect the content, and all legal disclaimers that apply to the journal pertain. 
ASD may be as common as 1 in every 152 children suggesting that these disorders pose "an urgent public health issue."

The reasons for the increase in the estimated prevalence over the past decades are not entirely clear, but several possibilities can be advanced to at least partially explain these increased rates. First, the early studies on prevalence relied on clinically identified cases rather than community-based surveys. Cases not in treatment were therefore missed; moreover, only the most severe cases were likely recorded. Second, even those studies that conducted community surveys used narrow case definitions. By contrast, more recent studies have used broader diagnostic criteria and better sampling methods, thus identifying more cases. Finally, recent studies have used better diagnostic instruments, which has served to improve differential diagnosis among the different spectrum disorders as well as helped to delineate ASD from other psychiatric disorders in children (Chakrabarti \& Fombonne, 2005). As more children with ASD are identified, there will likely be a rise in the number of children and families seeking treatment. Regardless of the cause(s) accounting for the higher prevalence estimates, therefore, clinicians are now faced with increasing numbers of children and teenagers with $\mathrm{ASD}$, and their families, who require assessment and effective treatment.

In the clinical setting, anxiety-related concerns are among the most common presenting problems for school-age children and adolescents with ASD (Ghaziuddin, 2002). Recognition of anxiety problems in this population is not new. Indeed, in his original description of children with "classic" autism, Kanner (1943) noted that a number of them had substantial anxiety problems. However, the evaluation and treatment of anxiety in this population has only recently received the empirical attention it deserves. There is an urgent need for the development of effective approaches to assess and treat children and adolescents with ASD (Lord et al., 2005), including treatments addressing associated problems such as anxiety.

Currently, anxiety is not considered a phenomenological characteristic of ASD. Although it is often assumed that individuals with ASD prefer isolation and low social contact, many people with ASD are intensely aware of their social disconnectedness and appear to wish it could somehow be different (Attwood, 2000). It is logical to conjecture that the social disability associated with ASD could engender anxiety - especially in higher functioning youth who have an awareness of their social disability. If a child has a co-occurring anxiety disorder, it could compound the overall social impairment associated with ASD. For example, social anxiety may contribute to avoidance of social situations, awkward interactions with peers, and promote further isolation from same-age peers (Myles, Barnhill, Hagiwara, Griswold, \& Simpson, 2001). Thus, anxiety may have bidirectional effects with the social disabilities of ASD. For these reasons, a developmental approach to understanding how anxiety develops, and how it may interact with the core disabilities of ASD, is important. This is also relevant clinically in as much as very high functioning adolescents with milder forms of ASD may present for clinical concerns due to anxiety, as opposed to the ASD per se.

An empirically based understanding of anxiety in children and adolescents with ASD is necessary to inform accurate assessment, case conceptualization, and treatment planning. To that end, this review summarizes research on anxiety in children and adolescents diagnosed with ASD. The specific aims are: (1) to summarize the empirical research on the prevalence, presentation, and treatment of anxiety in school-age children and adolescents with ASD; (2) to offer guidance on the 'next steps' for clinical research in this area; and (3) to provide clinical recommendations based on our understanding of anxiety in this population. 


\section{Methods}

This review was based on a systematic search of published articles available through August of 2008. The Psych-Info and Medline online databases were searched concurrently for entries containing any combination of the following terms: (1) autism, asperger(s), or pervasive developmental disorder and (2) anxiety or anxious. Abstracts of identified articles were then screened for the following inclusion criteria: (a) the target population included school-age children or adolescents (between 6 and 18 years) diagnosed with an ASD, including autism, Asperger's Disorder, or PDD-NOS; and (b) symptoms of anxiety in the youth were assessed with direct assessment or observation, or report (from parent, teacher, or child). There were no restrictions on minimum sample size. Theoretical papers on anxiety in ASD that were not databased, studies that examined populations not explicitly identified as having ASD (e.g., general developmental delay), unpublished dissertations, and secondary reviews were excluded, as were studies not published in English. To ensure full identification of relevant studies in the second phase of the literature search, three of the primary journals dedicated to the study of autism spectrum disorders were then searched for the keyword 'anxiety': the Journal of Autism and Developmental Disorders, Autism, and Focus on Autism and Other Developmental Disabilities. For brevity, the following abbreviations are used throughout this review: Autistic Disorder (AD), Asperger's Disorder/Syndrome (AS), Pervasive Developmental Disorder-Not Otherwise Specified (PDD-NOS), High-Functioning Autism (HFA), and Autism Spectrum Disorders (ASD).

The initial literature search resulted in 1349 citations. Of these, 38 met the inclusion criteria (direct assessment or report of anxiety in school-age children or adolescents diagnosed with ASD). Many of the unselected studies from the initial pool involved samples outside the targeted age range (e.g., adults or pre-school children) or with non-ASD developmental disabilities such as Fragile X Syndrome). The second phase, which systematically examined the three major autism journals, identified an additional two articles.

Because the purpose of the 40 studies varied, they were classified into three broad categories according to their primary research questions: prevalence, phenomenology, or treatment (see Tables 1, 2, 3, respectively). It should be noted that some of the studies addressed questions concerning more than one domain (e.g., phenomenology and treatment). In these instances, the studies were grouped and reviewed according to the focus of their primary research question. Eleven studies examined prevalence of anxiety problems in youth with ASD. Fifteen studies addressed phenomenology. Although several of these studies also reported the frequency of anxiety disorders, the reports in this category primarily examined clinical presentation, the characteristics of anxiety in youth with ASD, and the utility of specific measures to assess and diagnose anxiety disorders in ASD. Finally, 14 studies investigated treatment for co-occurring anxiety problems.

\section{Results \\ Prevalence}

Large-scale epidemiological studies have not been conducted on the prevalence of co-occurring anxiety disorders in ASD. However, the studies reviewed here indicate that between $11 \%$ and $84 \%$ of children with ASD experience some degree of impairing anxiety (Table 1). In the only studies to examine diagnosed anxiety disorders in ASD, deBruin et al. (2006) found that slightly more than 55\% of the sample met criteria for at least one anxiety disorder and Simonoff et al. (2008) reported an overall anxiety disorder diagnosis rate of almost $42 \%$. Some of the most frequently reported anxiety disorders and symptoms seen in children with ASD are simple phobias, generalized anxiety disorder, separation anxiety disorder, obsessive-compulsive disorder, and social phobia. Problems with anxiety are present across levels of cognitive 
functioning, although the type of anxiety problem is likely influenced by cognitive ability. Furthermore, in children with ASD, anxiety and specific fears are probably more associated with acting out behaviors than is the case for non-ASD children. There is some evidence that the prevalence of anxiety may differ across the specific diagnoses. Children with AS appear most likely to experience anxiety, followed by PDD-NOS, and then AD. These group differences must be interpreted cautiously given that diagnosis is often related to other factors such as level of cognitive functioning, which may also impact psychiatric comorbidity.

Given the high rates of psychiatric comorbidity, including anxiety disorders, in youth with ASD the utility of our current diagnostic schema is understandably of concern. Many Axis I anxiety disorders, such as social phobia and obsessive-compulsive disorder, are rarely diagnosed in people with spectrum disorders due to a general clinical consensus that such symptoms are better explained by the ASD itself. Further, some disorders (e.g., ADHD) explicitly cannot be dually diagnosed in $\mathrm{AD}$, given how frequently problems with inattention and overactivity are seen in children with $\mathrm{AD}$. Clinicians often have difficulty determining if symptoms (e.g., compulsive checking, social avoidance) should be conceptualized as part of the ASD or as a separate but co-occurring problem. Given the substantial symptom overlap and the lack of clarity in differential diagnosis, we see considerable variability in diagnoses. As identified by Leyfer and colleagues (2006), further research on the neurobiological bases, or biological markers, associated with 'comorbid conditions' in ASD should help us distinguish truly clinically distinct comorbid disorders from features associated with the ASD itself. The breadth of observed prevalence estimates is likely due to differences in sample ascertainment, study sample size, and how anxiety was operationalized and assessed. The study by Gadow, Devincent, Pomeroy, and Azizian (2005), for example, included children and adolescents from a developmental disorders specialty clinic $(n=301$; prevalence 19-25\%), whereas Bradley, Summers, Wood, and Bryson (2004) reported rates from a community sample ( $\mathrm{n}=12$; prevalence $42 \%$ ). Further, of the 12 studies examining prevalence most reported on 'symptoms' of anxiety based on a variety of measures rather than anxiety 'disorders' per se.

In terms of the method of assessment, most studies relied exclusively on parent-report measures, or a combination of parent- and other- or self-report measures (e.g., Bellini, 2004; Gadow et al., 2005; Lecavalier, 2006). Three studies compared the rate of anxiety symptoms and disorders in ASD to non-clinical populations via self-reported or informant-based assessment (Gadow et al., 2005; Kim, Szatmari, Bryson, Streiner, \& Wilson, 2000; Melfsen, Walitza, \& Warnke, 2006). Other studies did not utilize a control group but compared rates of anxiety disorders in the ASD group to non-clinical norms (e.g., Bellini, 2004). Kim et al. (2000) observed greater mood and anxiety symptoms in 59 children with AD or AS compared to typically developing children. In their study, Kim and colleagues normed the parent-report Ontario Child Health Study questionnaire, a revision of the Child Behavior Checklist (Achenbach \& Edelbrock, 1983), on a community sample of 1751 typically developing children such that $3 \%$ of the typically developing children obtained scores above the clinically relevant cutoff (i.e., two standard deviations above the mean). About $14 \%$ of the 59 youth in their ASD sample were above the standard cutoff for symptoms of generalized anxiety disorder. On the separation anxiety scale, $8.5 \%$ of the ASD children received clinically elevated scores. However, no differences in anxiety symptoms were observed between children diagnosed with AS and those with AD (Kim et al.). None of the children in this sample had intellectually disabilities, and Kim and colleagues reported that neither verbal ability nor nonverbal cognitive ability alone predicted later emotional problems.

In a sample of 41 adolescents with various spectrum disorders recruited from the Indiana Resource Center for Autism (a database of families of children with ASD) and from one Louisiana school district, Bellini (2004) reported that 20 youth (nearly half of the sample) had clinically significant levels of social anxiety as measured on the self-reported Social Anxiety 
Scale for Adolescents (SAS-A; LaGreca, 1999). Bellini also compared the scores from the ASD sample to normative data on the Multidimensional Anxiety Scale for Children (MASC; March, 1999), a self-report measure of anxiety, and the Behavior Assessment System for Children (BASC; Reynolds \& Kamphaus, 1992), a rating scale completed by parents. The adolescents with ASD had significantly higher scores, in comparison to the normative samples, on four domains of the MASC (physical symptoms, social anxiety, separation/panic, and total anxiety) as well as on the anxiety subscale and internalizing problems composite scale of the BASC. Although Bellini's sample was comprised of children with AD, AS, and HFA, no comparisons across diagnostic groups were reported.

Comparing the fears and behavior problems of children with ASD to those of children with other disabilities and to typically developing children, Evans, Canavera, Kleinpeter, Maccubbin, and Taga (2005) found that children with ASD had more fears than either children with Down's Syndrome who were matched on mental age or typically developing children matched on chronological age. This difference was confined to increased fears of specific situations such as small spaces and medical situations in the ASD sample. Furthermore, the behavioral problems of children with ASD were more related to the children's fears than was the case for the comparison groups. That is, externalizing problems (e.g., conduct problems, inattention) were more strongly correlated with parent-reported fears in the ASD sample than for children with Down's Syndrome or for typically developing children. These findings suggest that children with ASD may express fears or anxiety in externalizing behaviors, or perhaps simply that these problems are more likely to co-occur in ASD. Alternatively, parents of children with ASD may be more sensitive to the possibility that anxiety underlies behavioral disturbance and therefore be more likely to attribute behavioral disturbance to anxiety. This study, however, possesses some limitations that bear mention, and replication of these findings is sorely needed. The sample was recruited from a "program for children with autism" (Evans et al, p. 9) and the children had a variety of different spectrum conditions, with characterization based on parent report. Most of the children (21 of 25) with ASD had assessed IQs falling below 70, and sub-analyses based on functional level of the children in the ASD sample were not reported. Moreover, inclusion in the ASD sample was based on caregiver identification of the child as 'autistic' and ASD diagnoses were not confirmed by the investigators. Also, the children's fears were assessed with an unpublished parent report measure created for the study, which was comprised of seven subscales measuring fears of situations and places, harm, medical situations, animals, social situations, the environment, and strangers.

In one of the few studies to examine anxiety in lower functioning individuals, Bradley and colleagues (2004) assessed 12 children with both AD and severe intellectual disability. They compared the rates of psychiatric symptoms in children with $\mathrm{AD}$ and intellectual disability to a group of 12 individuals with intellectual disability but without $\mathrm{AD}$, both groups having a mean age of 16 years. Based on the Diagnostic Assessment for the Severely Handicapped (DASH-II; Matson, 1995), a structured interview to screen for psychiatric and behavioral disorders, the individuals with $\mathrm{AD}$ had higher levels of psychiatric symptoms than did the comparison group. The children with $\mathrm{AD}$ had an average of 5.25 clinically significant disorders (excluding AD) based on cutoff scores on the DASH-II, compared to an average of 1.25 for the non- $\mathrm{AD}$ group. On the anxiety subscale of the DASH-II, $42 \%$ of the sample with $\mathrm{AD}$ reached clinical significance compared to none of the individuals without AD (Bradley et al., 2004).

Gadow and colleagues (2005) used the Child Symptom Inventory-4 (CSI-4; Gadow \& Sprafkin, 2002), parent- and teacher-report measures, to assess the co-occurrence of DSM-IV psychiatric symptom clusters in a large sample of children with ASD $(n=301)$ ascertained from a developmental disorders specialty clinic. Children with ASD exhibited psychiatric symptom clusters at rates commensurate with, or higher than, children without ASD referred 
for outpatient psychiatric services. The ASD sample obtained significantly higher severity ratings in the areas of specific phobia, obsession, compulsion, motor and vocal tics, social phobia, and encopresis than did three comparison groups of children: psychiatric clinic referrals, regular education students, and special education students. Furthermore, a substantial number of children with ASD met screening cutoff scores for anxiety disorders on the CSI-4. Based on parent-report data, $25.2 \%$ of boys and $19.5 \%$ of girls with ASD exceeded the cutoff for generalized anxiety disorder (teacher report: $23.3 \%$ and $20.8 \%$ for boys and girls, respectively). For separation anxiety, $6.7 \%$ of boys and $7.1 \%$ of girls were above the screening threshold via parent-report (teacher report: $13.8 \%$ and $8.0 \%$, respectively). A strength of this study was the large sample, comprised of 103 children with AD, 80 with AS, and 119 with PDD-NOS. The authors reported that severity of ASD appeared to be negatively associated with psychiatric symptoms such that children with AD were generally rated as having fewer and less severe psychiatric symptoms (e.g., anxiety, depression) than children with PDD-NOS or AS. Of the three subtypes (AD, AS, PDD-NOS), the children with AS were rated by parents and teachers as the most psychiatrically impaired. Although IQ data were not available for all participants in this study, Gadow and colleagues found that children with higher IQs $(\geq 70)$ were rated as having greater psychiatric symptom severity. Unfortunately, IQ was not controlled for when examining ASD subtype differences in psychiatric symptoms. The degree to which the observed psychiatric severity differences across ASD diagnoses might be attributed to differences in cognitive functioning across the three diagnostic groups, therefore, is unknown.

Sukhodolsky and colleagues (2008) created a 20-item, parent-report anxiety scale from the Child and Adolescent Symptom Inventory (CASI) - a scale that combines the non-overlapping items of the CSI-4 (Gadow \& Sprafkin, 2002) and the Adolescent Symptom Inventory-4 (Gadow \& Sprafkin, 1997). The anxiety scale was developed to screen for eight anxiety disorders, while avoiding confounding assessment for other disorders such as ASD and ADHD. In other words, items were selected to assess anxiety exclusively. Drawn from two medication treatment trials, the children in the sample (ages 5-17) exhibited a broad range of cognitive functioning (e.g., 72\% had some degree of intellectual disability) and were primarily diagnosed with $\mathrm{AD}$ ( $88 \%$ of sample). Based on parent-report, 73 of the 171 children $(42.7 \%)$ met the cutoff on the screening scale for at least one anxiety disorder. Simple phobia was the most common disorder (31\% of sample met the cut-off), followed by social phobia (19.9\%). No age differences were found in anxiety severity. However, children with higher IQ and greater social impairment were found to experience the most severe anxiety (Sukhodolsky et al.).

Lecavalier (2006), using parent- and teacher-report ratings on the Nisonger Child Behavior Rating Form (Aman, Tasse, Rojahn, \& Hammer, 1996), reported on specific symptoms of anxiety seen in persons with ASD between the ages of 3 and 21 years. A large sample $(\mathrm{n}=$ 487) of individuals receiving educational services for ASD was drawn from 37 Ohio school districts. Based on parent- and teacher-report measures, respectively, the following percentages of persons scored in the moderate to severe range on three anxiety subscales: nervous/tense $(21 \%, 18 \%)$, fearful/anxious (17\%, 11\%), and worrying (14\%, 14\%). Although ASD diagnoses were not confirmed by the investigators, these findings suggest that anxiety symptoms are common in non-clinically referred students with spectrum disorders. Information on specific ASD diagnoses was not available, as all students between the ages of three and 21 who received educational services for pervasive developmental disorders were included in the sample. The investigators also examined the possibility of age effects in their sample. The only subscale that showed an age effect was insecure/anxious, on which younger children (ages three to six) earned significantly lower scores based on both parent and teacher report. With the sample ranging from 3 to 21 years of age, severity ratings increased with age and were highest in the group of 13- to 21-year-olds. Unfortunatley, no information on cognitive functioning level was provided. 
Examining the prevalence of social anxiety across different psychiatric disorders in children, Melfsen et al. (2006) used the German version (SPAIK; Melfsen, Florin, \& Warnke, 2001) of the Social Phobia and Anxiety Inventory (SPAIC; Beidel, Turner, \& Morris, 1995) in a sample of 341 clinically referred youth aged 7 to 18 years. On this measure of self-reported distress in various social situations, the subsample of seven children who were clinically diagnosed with AS by two psychiatrists had a mean SPAIK score of 20.77, which falls slightly above the clinical cutoff score of 20 indicative of social anxiety on the SPAIK (Melfsen et al., 2006).

The only other diagnostic subgroup to obtain a mean SPAIK score above the cutoff score were the nine children diagnosed with selective mutism.

Three studies used clinician-administered interviews to assess anxiety. Using the DISC-IV (Dutch version; Ferdinand \& Van der Ende, 1998), de Bruin and colleagues (2006) examined children with PDD-NOS and found that over $80 \%$ of the sample (76 of 94) had co-occurring psychiatric diagnoses. Although disruptive behavior disorders were most common (occurring in over $61 \%$ of the sample), anxiety disorders were a close second with slightly more than 55\% of the sample meeting criteria for at least one anxiety disorder. The most prevalent anxiety disorder in this sample was simple phobia, followed by social phobia and separation anxiety disorder. There was considerable variability in the assessed intelligence of the sample, with full scale IQs ranging from 55 to 120 (mean=91). There were no significant differences in IQ, however, between those children with PDD-NOS who had comorbid internalizing or disruptive behavior disorders and those who did not. In a second study, Muris, Steerneman, Merckelbach, Holdrinet, and Meesters (1998) administered the Anxiety Disorders section of the Diagnostic Interview Scheduled for Children (DISC; National Institute of Mental Health, 1992) to children $(\mathrm{n}=44)$ with ASD. Children in the sample were diagnosed with either AD or PDD-NOS based on DSM-III-R criteria (American Psychiatric Association, Diagnostic and Statistical Manual of Mental Disorders-3 ${ }^{\text {rd }}$ Edition, Revised, 1987). Of the 44 children, 37 met criteria for at least one anxiety disorder. The most common disorders were simple phobia $(\mathrm{n}=28)$, agoraphobia $(n=20)$, separation anxiety disorder $(n=12)$, and overanxious disorder/GAD $(n=10)$. Muris and colleagues reported that some anxiety disorders were more frequently seen in children with PDD-NOS than in those with AD (e.g., simple phobia, separation anxiety disorder). However, the two groups differed in terms of age and intellectual functioning making direct comparisons difficult: the children with PDD-NOS had significantly higher IQs and were older than the children with AD.

Simonoff and colleagues (2008) assessed the prevalence of comorbid psychiatric disorders, based on DSM-IV criteria (American Psychiatric Association, 2000), in a population-derived sample of children with confirmed ASD diagnoses. The Child and Adolescent Psychiatric Assessment (CAPA) interview was administered to the parents of 112 children with either PDD-NOS $(n=50)$ or AD $(n=62)$, between the ages of 10 and 14 . The most commonly cooccurring psychiatric disorder was social anxiety disorder, with $29.2 \%$ of the sample meeting criteria, followed by ADHD and oppositional defiant disorder. Among other assessed anxiety disorders occurring in at least $10 \%$ of the sample, $13.4 \%$ had generalized anxiety disorder and $10.1 \%$ panic disorder. ASD diagnosis (AD or PDD-NOS), IQ, and adaptive behavior were not associated with the presence of an anxiety disorder. These results indicate that anxiety disorders are common in the broader ASD population, not just clinical cases.

\section{Phenomenology}

Studies examining the phenomenology of anxiety, including its assessment and diagnosis, confirm that anxiety is not a rare occurrence in children with ASD. There are very likely age and IQ effects on the presentation of anxiety, with younger children experiencing milder anxiety (based on parent-report), and cognitively higher functioning children experiencing more anxiety than children with ASD who are cognitively lower functioning. There may also 
be ASD diagnostic subgroup differences. Weisbrot and colleagues (2005) found that anxiety problems were more apparent in children with AS than in those with AD. Thede and Coolidge (2006) reported that children with AS in their sample had more Axis I and Axis II characteristics in which anxiety was the underlying factor than did children with HFA. There is emerging evidence for relationships among anxiety, sensory hypersensitivity (Pfeiffer, Kinnealey, Reed, $\&$ Herzberg et al., 2005), and degree of social impairment (Bellini, 2006). Studies have also found a strong relationship among negative automatic thoughts, anxiety symptoms, behavioral problems, and life interference in children with ASD (Farrugia \& Hudson, 2006).

Collectively, these studies indicate that different respondents can give quite disparate ratings of anxiety. In a study of comorbidity in children with ASD, Gadow and colleagues (2005) found that teachers gave higher symptom ratings of anxiety, depression, and tics, than did parents. Such behaviors may be somewhat context-dependent; for example, children may feel more anxious in school environments when around peers or in academically demanding situations. Or the discrepancy may be a function of rater bias, especially so if parents downplay the significance of certain behaviors or lack a comparison benchmark. In these studies, a multitude of different measures have been used to assess anxiety, none of which were specifically designed to assess children with ASD. Most studies employed paper and pencil survey measures, usually relying on the parent as informant. Difficulties with emotional insight, or the ability to accurately detect and interpret one's own emotions, are thought to be characteristic of ASD. Many individuals with ASD have unique processing and sensory profiles, and symptoms of anxiety are very likely expressed differently in people who have autism or a related condition in comparison to non-ASD children.

Table 2 presents results from 15 studies focused on the presentation and diagnosis of anxiety in youth with ASD. Similar to the studies examining prevalence, most of these reports (13 of 15) relied on parent-, self-, or teacher-report measures of anxiety. One study (Green, Gilchrist, Burton, \& Cox, 2000) used clinician interviews and one (Kanai et al., 2004) used direct behavioral observations. In the only study to compare children with ASD to a sample of children with diagnosed anxiety disorders, Farrugia and Hudson (2006) examined cognitive factors associated with anxiety. Using both parent- and self-report measures of anxiety, automatic thoughts, behavioral problems, and level of life interference, they compared adolescents with AS $(n=29)$ to non-clinical $(n=30)$ and anxiety disordered $(n=34)$ samples of adolescents. After noting the high correlation between parent- and self-report measures in their results, the investigators used the teen self-reports in subsequent analyses. The adolescents with AS reported more symptoms of anxiety than the non-clinical control group but remarkably similar anxiety symptoms to the youth with anxiety disorders. Based on the Spence Children's Anxiety Scale (SCAS; Spence, 1998), the children with AS scored highest on symptoms of obsessive-compulsive disorder, followed by symptoms of social phobia and generalized anxiety disorder. The AS sample also reported more behavioral problems and more negative automatic thoughts than the comparison groups. Furthermore, the correlations among anxiety symptoms, negative automatic thoughts, behavioral problems and overall impairment were significantly higher in the AS group than in either comparison group.

Several of the studies addressing phenomenology employed control groups comprised of other clinical samples (not anxiety-disordered) or of typically developing children. Williamson, Craig, and Slinger (2008) used the SCAS (Spence, 1998) to compare 19 adolescents with AS to 19 typically developing students matched on age, ethnicity, and sex recruited from a sample of secondary school students. No group differences in total anxiety were found, but the AS sample did report significantly more obsessive-compulsive symptoms on the SCAS. For the youth with AS, parent-relevant competencies (scholastic competence, behavioral conduct), but not peer-relevant competencies (e.g., social competence), were predictive of anxiety scores. Weisbrot, Gadow, DeVincent, and Pomeroy (2005) examined the presentation of specific types 
of anxiety symptoms in 483 children with ASD. Within the sample, there were a good number of children falling in each ASD subtype (AD: $n=170$, AS: $n=104$, PDD-NOS: $n=209$ ), with clinical diagnoses made by a child psychiatrist. One goal of the study was to determine if children with ASD were at greater risk for anxiety problems than other clinically referred children without a diagnosis of an ASD. Another important aim was to learn more about the boundaries between anxiety symptoms and psychotic symptoms in children with ASD. The investigators proposed that the communication deficits in children with ASD could pose a challenge in trying to differentiate anxious worries from thought disorders. On the other hand, it was hypothesized that reality testing could be compromised in children with ASD who also had an anxiety disorder.

In the Weisbrot et al. (2005) study, the medical records of children with ASD ascertained from a university-based specialty clinic and a child psychiatry outpatient clinic were systematically reviewed. Parents and teachers were given the Early Childhood Inventory-4 (ECI-4; Gadow $\&$ Sprafkin, 1997) for children between three and five years of age or the Child Symptom Inventory-4 (CSI-4; Gadow \& Sprafkin, 2002) for children ages 6 to 12 years. Both measures are broad-based rating scales that screen for major DSM-IV disorders. Children with AS (ages 6 to 12) earned higher ratings based on both parent- and teacher-report on several anxiety items, primarily those assessing generalized anxiety disorder, than children diagnosed with $\mathrm{AD}$ (Weisbrot et al.). Although parents of younger children (3- to 5-year-olds) with ASD did not report as many anxiety symptoms as did parents in the non-ASD sample, the children's teachers rated them as more anxious than the clinically referred, non-ASD children. The 6- to 12-yearolds with ASD who were rated as highly anxious by their parents and teachers also received more severe ratings of psychotic symptoms (e.g., delusions, inappropriate affect) compared to children with ASD with low levels of anxiety. Further exploratory analyses revealed that children with the highest levels of anxiety had higher mean IQ scores than did the low-anxious ASD group. For children without ASD, there was no difference in severity of anxiety symptoms across IQ groups. Results of this study indicate that children with ASD may experience anxiety symptoms similar to those seen in non-ASD clinical samples, but that the presentation of anxiety symptoms in this population may be affected by age and cognitive functioning. The high-anxious 6- to 12-year-olds also received significantly higher ratings of psychotic symptoms (e.g., inappropriate affect, auditory hallucinations), based on teacher- and parentreport, compared to less anxious children with ASD. When severity of ASD symptoms was controlled for, the same pattern held, with the exception that teacher ratings of grossly disorganized behavior were no longer significant. Weisbrot et al. noted that highly anxious, non-ASD children also received elevated ratings of psychotic symptoms compared to their less anxious, non-ASD peers, and concluded that anxiety and thought disorders may present similarly in ASD and in non-ASD children, supporting the notion that such disorders should be viewed as co-occurring conditions rather than as epiphenomena of ASD.

To examine the nature of anxiety in school age children with HFA, Gillott, Furniss, and Walter (2001) administered the Spence Children's Anxiety Scale (SCAS; Spence, 1997) to assess overall anxiety, and the Spence Social Worries Questionnaire (SWQ; Spence, 1995) to assess social anxiety. The study sample consisted of 15 children with HFA and two age- and gendermatched comparison groups: 15 children with specific language impairment and 15 typically developing children (mean age of each group $=10$ years). Youth with HFA obtained higher scores on the SCAS than the comparison groups. Seven of the 15 children with HFA scored at threshold or higher for the cutoff for anxiety disorders. The highest subscale score elevations were for obsessive-compulsive disorder and separation anxiety. The children with HFA also self-reported more social worries than either comparison group. The results of this study indicate that high-functioning children on the spectrum exhibit social worries both covertly (e.g., ruminating) and overtly (e.g., actively avoiding social interaction with peers). 
In the only study that examined the relationship between anxiety and processing deficits in youth with ASD, Burnette et al. (2005) tested relationships among weak central coherence, theory of mind abilities, and social anxiety. The sample of 31 youth with HFA included children with history of language delay or impairment as well as children with no language impairment. Weak central coherence, as described by Frith (1989), suggests that individuals with autism have deficits in integrating specific details into a unified whole, which may lead to social information processing problems (e.g., difficulty interpreting language out of context). Burnette et al. hypothesized that weak central coherence would be correlated with anxiety symptoms in children with HFA. Significantly more youth self-reported symptoms of social anxiety on the Social Anxiety Scale for Children-Revised (SASC-R; La Greca \& Stone, 1993), compared to a control group of children with learning disabilities and children with typical development. In contrast, no group differences were found in anxiety symptoms on the self-reported Behavioral Assessment System for Children Self-Report of Personality (BASCSRP; Reynolds \& Kamphaus, 1998), although the teens with HFA did report less competence and satisfaction in interpersonal relationships. There was no apparent association between anxiety and weak central coherence, and results showed equivocal support for the weak central coherence hypothesis. Burnette and colleagues noted that the findings of this study, specifically that the HFA sample did not demonstrate weak central coherence deficits on visual-spatial tasks, may have been influenced by the heterogeneous nature of the group (i.e., including youth with $\mathrm{AD}$ and youth with AS). Therefore, the lack of a relationship between anxiety and weak central coherence may be due to characteristics of the sample.

Green et al. (2000) used modified Isle of Wight Semistructured Informant and Child Interviews to interview both parents and youth on presence of emotional and behavioral problems. The sample included 20 boys with AS and 20 boys with conduct disorder, all of whom were clinically referred. The frequency of psychiatric symptoms was equally high in both groups. The adolescents with AS, however, had significantly more symptoms of anxiety than did adolescents with conduct disorder. Just over half (11 of 20 participants) of the AS group had two or more symptoms of anxiety.

In a study designed to examine associations between information processing, social functioning and psychological functioning, including co-occurring psychiatric disorders, Meyer, Mundy, Van Hecke, and Durocher (2006) compared 31 children with AS (mean age $=10$ years) to 33 typically developing children matched on age. These investigators found that anxiety was related to deficits in social awareness and experience. Using the Behavioral Assessment System for Children (BASC: parent-report \& self-report; Reynolds \& Kamphaus, 1998), the teens with AS and their parents reported higher levels of anxiety than did the control group. The study also asked participants to review brief vignettes in order to assess the children's social understanding and attributions. The children with AS demonstrated poorer psychosocial adjustment and evinced more emotional-behavioral problems than age- and ability-matched peers.

More than half of the reviewed phenomenology studies did not use a control group for comparison (Table 2). Still, these studies reveal important descriptive characteristics of the youth. In one of the few studies that integrated paradigms from occupational therapy and clinical psychology, Pfeiffer and colleagues (2005) assessed both sensory modulation and emotional functioning in a clinical sample of 50 children and teens with AS. They found that sensory hypersensitivity was significantly correlated with parent-reported anxiety symptoms $(\mathrm{r}=.48, \mathrm{p}<.001)$. Thus, heightened sensitivity to environmental stimuli and sensory modulation dysfunction appear to be related to anxiety in people with AS, although the apparent association and direction of causality require further investigation. 
In a sample of 41 adolescents diagnosed with ASD, including 19 with AD, 16 with AS, and 6 with PDD-NOS, Bellini (2006) examined the association of social skill deficits and physiological hyperarousal associated with social anxiety. The Social Anxiety Scale for Adolescents (SAS-A; LaGreca, 1999) was used to assess symptoms of social anxiety, and the Multidimensional Anxiety Scale for Children (MASC; March, 1999) was used to assess broad symptoms of anxiety. Using multiple regression, Bellini found that physiological arousal (assessed via the Physical Symptoms subscale of MASC) and social skills deficits combined to significantly predict social anxiety scores (adjusted R square $=.34$ ). Based on these findings, it appears that physiological arousal along with social skill deficits can contribute to the selfreported social anxiety often present in teens with ASD. No differences across the three diagnostic groups were reported.

In light of some evidence suggesting limbic system involvement in the expression of ASD, Juranek and colleagues (2006) studied the relationship between amygdala volume and parentreported anxiety/depression scores in a well-characterized sample of children with AD. In their sample of 42 children with confirmed diagnoses of $\mathrm{AD}$, symptoms of anxiety and depression as measured by the Child Behavior Checklist (Achenbach, 1991) were significantly correlated with increased total amygdala volume and right amygdala volume in particular. Anxiety was not correlated with left amygdala volume. Significant correlations were not found for other syndromal scales, suggesting that the relationship between anxious/depressed symptoms and amydala volume is specific.

In a sample of 65 children (ages 10 to 13) diagnosed with AS but without clinical diagnoses of anxiety disorders, Russell and Sofronoff (2005) assessed the concordance of parent- and child-reported symptoms of anxiety. They also compared the AS sample to typically developing children and children with social phobia. Both the parents and the children completed the Spence Children's Anxiety Scale (SCAS; Spence, 1997) and the Social Worries Questionnaire (SWQ; Spence, 1995). According to self- and parent-reports, children with AS displayed significantly more problems with anxiety than did typically developing children. There were no significant differences in anxiety symptoms between children with AS and those with social phobia, based on child self-report. Parent-report, however, resulted in higher ratings of overall anxiety and more obsessive-compulsive symptoms in the AS group compared to those with anxiety disorders. Parents and children with AS also disagreed on their assessment of social worries; the parents reporting more social worries than the children with AS selfreported. The investigators concluded that although children with AS may experience and endorse significant anxiety, they may lack insight about the potential connection between social deficits and anxiety. For this reason, Russell and Sofronoff suggested that parent reports of children's anxiety and social worries might be more accurate.

Four studies examined differences in anxiety symptoms across ASD diagnoses (Kanai et al., 2004; Pearson et al., 2006; Thede \& Coolidge, 2006; Tonge, Brereton, Gray, \& Einfeld, 1999). Kanai and colleagues reported that children with PDD-NOS $(n=53)$ exhibited stronger anxiety reactions than did children with $\mathrm{AD}(\mathrm{n}=21)$ as measured on the Childhood Autism Rating Scale (CARS-Tokyo Version; Kurita, Miyake, \& Katsuno, 1989). The investigators were careful to exclude individuals with intellectual disability (i.e., IQ $<70$ ). The conclusions from this study are limited, however, because only a single item on the CARS was used as the dependent variable of anxiety reaction. Tonge et al. examined differences in psychopathology between children with HFA $(n=75)$ and children with AS $(n=52)$. All participants had fullscale IQ scores above 70, and diagnoses were confirmed by multiple raters. Psychopathology was assessed via the parent-report Developmental Behaviour Checklist (DBC; Einfeld \& Tonge, 1994). Although both groups exhibited considerable psychopathology (i.e., $65 \%$ and $85 \%$ of the HFA and AS groups, respectively, had clinically significant levels of disturbance), the children with AS were rated as having more overall psychopathology than the children with 
HFA. The group with AS also received significantly higher scores on the disruptive, anxiety, autistic/social relating, and antisocial subscales of the DBC.

Pearson and colleagues (2006) assessed 51 children with ASD using the parent-reported Personality Inventory for Children-Revised (PIC-R; Wirt, Lachar, Klinedinst, \& Seat, 1984) to compare the behavioral and emotional functioning of children with $\mathrm{AD}(\mathrm{n}=26)$ to those with PDD-NOS $(n=25)$. After controlling for verbal IQ (children with PDD-NOS had significantly higher verbal IQ scores), the children with AD had significantly more social difficulties, atypical behaviors, and social withdrawal (the core symptoms of autism), than did the children with PDD-NOS. There were no mean differences in anxiety symptoms across groups; however, the means of both groups approached the clinically significant threshold for anxiety symptoms. Over one-third of the children with AD and one-half of those with PDD-NOS were rated in the clinical range for anxiety on the PIC-R. Verbal IQ was not found to correlate with parentreported anxiety problems in the sample.

Thede and Coolidge (2006) compared children with HFA $(n=15)$ to those diagnosed with AS $(n=16)$ on parent-report measures of psychological and executive functioning. Based on parentreport of diagnosis and a 44-item survey of autistic symptoms created for the study, children were determined to have either HFA or AS. The primary determinant of assignment to the AS or HFA groups was language delay; all of the children in the HFA group had parent-reported language delays. The Coolidge Personality and Neuropsychological Inventory (CPNI; Coolidge, Thede, Stewart, \& Segal, 2002), a measure of personality and neurobehavioral deficits based on DSM-IV-TR (APA, 2000) criteria, was administered to the parents of the children with ASD and an age- and gender-matched control group. The only significant difference found between the children with HFA and those with AS was on the CPNI generalized anxiety disorder domain with the AS group being more anxious than the HFA group. Children with AS also had higher scores on the obsessive-compulsive, avoidant, and depressive personality scales. Both groups (AS and HFA) scored significantly higher than the control group on schizoid and schizotypal subscales. Similarly, the ASD children (AS and HFA combined) showed greater deficits than the control children on the Executive Function scale of the CPNI. However, there were no significant differences in executive functioning between the AS and HFA children. Summarizing the differences between the children with AS and those with HFA, Thede and Coolidge concluded that children with AS are at greater risk for anxiety disorders and related personality disorders (obsessive-compulsive and avoidant traits). The reliance on parent report of diagnosis, however, along with use of an unpublished parentreport symptom scale to delineate the clinical groups should be noted as limitations of this study.

\section{Treatment}

There are presently no empirically supported treatments that target the behavioral and emotional concerns frequently presented by school-age children and adolescents with ASD, including anxiety. Pharmacological studies have reported preliminary evidence for the efficacy of sertraline, an SSRI (e.g., Bhardwaj et al., 2005; Ozbayrak, 1997), buspirone (Buitelaar et al., 1998), and dextromethorphan (Woodard et al., 2005). However, none of these studies included a control group or placebo condition, and the largest sample size was 22 (Buitelaar et al.). Thus, conclusions based on this research are tenuous at best. Psychosocial treatments have also been investigated. Cognitive-behavioral interventions show promise as an effective treatment modality for co-occurring anxiety in ASD. These studies, however, have been conducted with higher functioning, generally older children with ASD. There is little available guidance on how to clinically address anxiety in younger children and those who are intellectually impaired. 
In typically developing children, anxiety has received considerable research attention and there are empirically supported treatment options available, including pharmacological and psychosocial approaches (Foa et al., 2005; Ollendick \& King, 1998; Silverman, Pina, \& Viswesvaran, 2008; Velting, Setzer, \& Albano, 2004). By adapting such interventions for children and adolescents with ASD and comorbid social anxiety, clinicians may be able target this group of individuals more effectively. Attwood (2003) has written extensively on modifying and individualizing traditional cognitive-behavior therapy (CBT) approaches for the cognitive and emotional profiles of children with ASD. Clinicians have begun to consider how CBT for problems associated with anxiety can be successfully applied to help adolescents who have ASD (Greig \& MacKay, 2005). However, none of the studies in this review implemented an intervention program that was developed specifically for youth with ASD. Interventions developed initially for other clinical populations were adapted for people with ASD.

Intervention studies for anxiety in ASD can be grouped into three types: psychopharmacological, psychosocial, and alternative (Table 3). Psychopharmacological interventions have consisted largely of uncontrolled case studies. The selective serotonin reuptake inhibitors (SSRIs) have received considerable attention in the treatment literature. A case report of two children treated with sertraline (daily doses 25 to $50 \mathrm{mg}$ ) reported improvements in symptoms of anxiety (Ozbayrak, 1997). The children, ages 6 and 13 years, were diagnosed with AS based on DSM-IV criteria and both had co-occurring symptoms of anxiety (e.g., frequent need for reassurance, clinging to primary caretaker). Anxiety symptoms decreased following monotherapy sertraline treatment. No objective measures or parentreports were apparently obtained to assess anxiety symptoms, however; only clinician observations were reported. Bhardwaj, Agarwal, and Sitholey (2005) provided a clinical case report of an 11-year-old girl with AS who had difficulty separating from her younger sister. Based on the Kiddie Schedule for Affective Disorder and Schizophrenia-Present and Lifetime version (KSADS-PL; Kaufman, Birmaher, \& Breut, 1997), the girl met criteria for a diagnosis of separation anxiety disorder. After approximately eight weeks of treatment with sertraline (150 mg daily), there was a decrease in anxiety symptoms, again based solely on clinical observation.

Kauffmann, Vance, Pumariega, and Miller (2001) reported results from a single case study of a 7-year-old girl with PDD-NOS and intellectual disability treated with fluvoxamine. From baseline to 10-week follow-up, the child demonstrated improvements on all subscales of the parent-reported CARS (Childhood Autism Rating Scale; Schopler, Reichler, \& Renner, 1986), with a 15.5-point decrease in the total CARS score. The child displayed significantly fewer aggressive behaviors and also less nervousness, although the authors pointed out that the fluvoxamine may not have been very effective in reducing repetitive behaviors or anxiety (Kauffmann et al., 2001). It was also briefly noted that the child's parents and teachers received concurrent training and behavior interventions, which may have contributed to observed behavior changes. Namerow, Thomas, Bostic, Prince, and Monuteaux (2003) conducted an unblinded, retrospective chart review of 15 outpatients diagnosed with various ASD diagnoses who were treated with citalopram. The authors used Clinical Global Impressions (CGI; Guy, 1976) severity and improvement ratings to compare baseline to final treatment ratings. They found that symptoms of anxiety (e.g., preoccupations, repetitive behaviors) were most responsive to treatment, with 10 of the 15 youth exhibiting significant improvement with citalopram treatment (range: $5 \mathrm{mg}$ - $40 \mathrm{mg}$ daily; 14-621 days of treatment).

Silveira, Jainer, and Bates (2004) treated a 6-year-old girl with an unspecified ASD who was also diagnosed with selective mutism and social anxiety with fluoxetine (up to $20 \mathrm{mg}$ daily). After eight weeks, her parents reported improvements in symptoms of anxiety and selective mutism; she was speaking at school and in other environments, had improved eye contact, and 
smiled more. A retrospective study of the effectiveness of citalopram reported that 10 of 17 children with ASD who were treated with the SSRI (doses ranged from 5-40 mg daily) showed improvement in target symptoms (Couturier \& Nicolson, 2002). Of the 17 children in the sample, eight had been previously diagnosed with intellectual disability and most were diagnosed with $\mathrm{AD}$. This study conducted an unblinded chart review of children who were previously treated for a variety of target symptoms, such as aggression and anxiety. The study authors reported that the target symptoms most likely to improve with citalopram treatment were anxiety and aggression.

Buitelaar, van der Gaag, and van der Hoeven (1998) conducted an open trial of buspirone to treat anxiety and irritability in children with ASD. All 22 youth (20 with PDD-NOS, 2 with $\mathrm{AD}$ ), exhibited chronic problems with anxiety, irritability, and/or affective dysregulation. Following six to eight weeks of buspirone treatment with doses ranging from 15 to $45 \mathrm{mg}$ daily, 16 of the 21 individuals to complete the trial showed a positive response: nine had marked improvement and seven had moderate improvement on the Clinical Global ImpressionsImprovement scale (CGI-I; Guy, 1976). Another clinical case study of a 10-year-old boy diagnosed with $\mathrm{AD}$ and generalized anxiety disorder reported improvements in target behaviors, leaving the classroom and aggressive tantrums, following treatment with dextromethorphan $30 \mathrm{mg}$ per day in divided doses (Woodard, Groden, Goodwin, Shanower, $\&$ Bianco, 2005). This familiar antitussive agent has been reported to be helpful in case reports on people with neurodevelopmental disorders (e.g., Welch \& Solvner, 1992). Although the mechanism of effect is unclear, the authors postulated that the dextromethorphan may have relieved discomfort associated with other illnesses or that the secondary sedative effects resulted in behavioral improvements. Given that dextropethorphan is a glutamate receptor antagonist, however, a third plausible explanation for these results put forth by the authors is related to glutamatergic dysfunction, which may be relevant to ASD (e.g., McDougle, 2002; Woodard et al.). Johnson and Hollander (2003) reported on a case study in which fish oil supplements with omega-3 fatty acids were added to the ongoing treatment program of an 11year-old boy with AD. Following stabilization of behavior with risperidone and topiramate, the addition of the supplement ( $1 \mathrm{~g}$ to $3 \mathrm{~g}$ daily) resulted in "complete elimination" of the boy's anxiety and agitation (p. 849). Results were based on parent report and clinician observation.

The primary psychosocial treatments examined to date have employed CBT. Two case studies examined CBT for obsessive-compulsive disorder (OCD). In the first study, Reaven and Hepburn (2003) modified exposure and response prevention for a seven year-old girl with AS, emphasizing use of visual aids and parent involvement. Based on parent and child interview of symptoms using the Children's Yale-Brown Obsessive Compulsive Scale (CY-BOCS; Scahill et al., 1997), the girl's OCD symptoms decreased by $65 \%$. The second case study also implemented modified exposure and response prevention, with a 12-year-old boy with AD (Lehmkuhl, Storch, Bodfish, \& Geffken, 2008). The boy's symptoms improved substantially based on CY-BOCS (Scahill et al., 1997) scores, which dropped from moderately severe pretreatment (score of 18) to within normal limits (score of 3) at endpoint. The Child ObsessiveCompulsive Impact Scale (COIS; Piacentini, Bergman, Keller, \& McCracken, 2003) selfreport also showed improvement (COIS score decreased from 40 to 3 ).

Chalfant, Rapee, and Carroll (2006) evaluated a 12-week, group-delivered cognitivebehavioral treatment for anxiety in youth with ASD (HFA and AS) in a randomized controlled trial. The youth $(n=47)$ were school-age children with ASD without intellectual disability. Based on the ADIS (Albano \& Silverman, 1996) at pre-treatment, over 74\% of the sample met criteria for more than one anxiety disorder. Compared to individuals in the wait-list control group, children who received CBT showed significant reductions in anxiety symptoms (Chalfant et al.). The intervention was adapted for children with ASD from Lyneham, Abbott, Wignall, and Rapee's (2003) "Cool Kids" program for the treatment of childhood anxiety. At 
post-treatment, $71.4 \%$ of the treated youth $(\mathrm{n}=28)$ no longer met criteria for an anxiety disorder, compared to $0 \%$ in the wait-list condition $(\mathrm{n}=19)$. Of note, ASD diagnoses were not confirmed by the researchers, as participants were accepted into the program based on previous evaluations done within the community setting. This limitation notwithstanding, the study demonstrated that CBT is a promising intervention for treating anxiety in children with ASD without mental retardation. Cognitive strategies were simplified in the intervention, with a greater focus on visual aides, structured worksheets and homework, and exposure. Chalfant et al. found that the children were largely able to identify their automatic thoughts, indicating some 'theory of mind' ability, and subjects in the CBT condition had a significant reduction in automatic thoughts, in comparison to the wait-list condition.

Sofronoff, Attwood, and Hinton (2005) evaluated the impact of a six-week cognitivebehavioral intervention for anxiety in 71 school-age children with AS. The additional potential impact of parent involvement on outcome was also evaluated. Children were included in this study if they had a diagnosis of AS (confirmed via a semi-structured telephone interview) and anxiety symptoms based on parent report in the initial telephone interview. Participants were randomly assigned to one of three groups: child-based intervention, child + parent (child-based intervention which also included the parent), or wait-list. The intervention was delivered weekly in a group format, and focused on teaching the children strategies to effectively manage feelings (e.g., creating a 'tool box' of coping strategies to access when needed) and expanding emotional knowledge (e.g., comparing emotions in different situations). In the child + parent condition, parents were trained in all parts of the intervention and the parents subsequently served as their children's co-therapists. Based on the Spence Child Anxiety Scale-Parent report (SCAS-P; Spence, 1997), children in the combined (parent + child) intervention reported fewer symptoms of anxiety post-treatment and at a six-week follow-up than children in the childonly intervention. One child-report measure ('James and the Maths Test'; Attwood, 2002) was used to assess the number of strategies the child could identify for coping with anxiety. Children who received either intervention were able to develop more coping strategies at endpoint compared to the wait-list children, and those in the combined intervention generated significantly more coping strategies than participants in the child-only condition. The authors noted that, for many children who received either intervention (child alone or parent + child), significant improvement did not occur until the follow-up assessment six weeks after treatment ended, suggesting that skill implementation and symptom reduction may be delayed. The reliance on parent-report of anxiety symptoms is a limitation, in that parents who were involved in the treatment delivery may have been more invested in their children's progress and may have had strong expectations for improvement. Nonetheless, this study provided preliminary evidence that parent involvement in the delivery of treatment targeting anxiety in children with ASD can enhance effectiveness. Collateral parent involvement may build parents' confidence as well as their ability to help their children. For example, parents who are trained as 'cotherapists' may be better able to prompt and coach their children's use of skills at home and in other naturalistic environments.

Finally, only one published study could be found on an alternative treatment approach for anxiety in children with ASD. Edelson, Edelson, Kerr, and Grandin (1999) used Temple Grandin's Hug Machine, a device that applies deep lateral body pressure, as a treatment for high arousal and anxiety level. Twelve children with $\mathrm{AD}$, half of whom were either nonverbal or verbally impaired, were randomly assigned to treatment with the Hug Machine or to placebo (provided via a disengaged Hug Machine). Compared to the control group, the children in the treatment group showed significant declines for the tension and hyperactivity-restlessness subscales of the Conners Parent Rating Scale (Conners, 1970), but only a marginally significant reduction in anxiety. As mean pre-intervention and post-intervention scores were not provided in the report, magnitude of change cannot be estimated. Despite random assignment to condition, the children in the treatment group had significantly higher anxiety and tension 
scores at pre-test than did the control group. It was concluded that deep pressure treatment may be most helpful to children with AD who have very high levels of anxiety or over-arousal. In addition to the small sample size, the results of this pilot study have not been replicated to date.

\section{Discussion}

Although the relationship between ASD and anxiety is not fully understood at this time, it is evident that anxiety is a problem for a substantial number of individuals with ASD. This review was undertaken to: (1) identify areas in which further research is needed, with consideration of some of the methodological limitations seen across the studies reviewed; (2) draw general conclusions about the prevalence, phenomenology, and treatment of anxiety in ASD based on the reviewed literature; and (3) recognize relevant clinical implications. Based on the data presented in these studies collectively, there is no question that anxiety problems are quite prevalent in young people with ASD, with comorbidity estimates ranging from 11 to $84 \%$. Variables such as specific ASD diagnosis, level of cognitive functioning, and degree of social impairment likely have an influence on the individual's experience of anxiety. Unfortunately, there is little clarity on how best to assess symptoms of anxiety in this population. Although still a relatively new area of study, medical and therapeutic interventions have demonstrated promising pilot results for many youth with ASD and anxiety.

\section{Methodological Issues and Future Research}

The studies summarized in this review have addressed a broad range of questions about anxiety in young people with ASD. In reviewing this literature, our intent was to not only summarize the available empirical literature but also inform future research. By addressing methodological issues that limit the findings of the extant literature, future studies can contribute substantially to our understanding of anxiety in this population and answer more pointed scientific questions. Few of the reviewed studies (e.g., Bradley et al., 2004; Kim et al., 2000) reported using 'gold standard' diagnostic tools for ASD (i.e., Autism Diagnostic Interview-Revised [ADI-R; Lord, Rutter, \& LeCouteur, 1994] and Autism Diagnostic Observation Schedule [ADOS; Lord et al., 2000]). Some studies did not employ any independent confirmation of the diagnoses, instead including children based solely on previous clinical diagnoses of ASD (e.g., Bellini, 2006; Kanai et al., 2004). Other studies, such as Gadow et al. (2005), used rigorous diagnostic evaluation procedures (e.g., interview, observations) and established inter-diagnostician reliability, but did not use the ADI-R or ADOS, which were designed specifically for the assessment of autism and other spectrum conditions.

The studies reviewed demonstrated little consistency in terms of how anxiety symptoms were measured, and considerable variability in how respondents (e.g., parent, child) perceived such symptoms. Research on the applicability of traditional measures of childhood anxiety is sorely needed, as is research on the sensitivity of existing measures to changes in target symptoms (Lord et al., 2005; Wolery \& Garfinkle, 2002). If valid and reliable measures cannot be identified, new measures will need to be developed in order to accurately capture symptoms of anxiety in people with ASD. Until we have consensus on 'best practice' measures, a healthy skepticism is called for with respect to the precision of the tools we currently have for measuring childhood anxiety when evaluating children with ASD.

A methodological concern seen in most of the studies is inclusion of mixed ASD samples, comprised of youth with AD, AS, and PDD-NOS. Although many of the studies reported on the specific ASD diagnoses of the children in their samples, relatively few established the reliability of diagnosis or compared functioning across the specific diagnostic categories. Farrugia and Hudson's (2006) sample, for example, was comprised of adolescents only with AS; however, diagnoses from the community were accepted and were not confirmed as part of the study. Based on the studies that did compare diagnostic groups, differences in how 
anxiety was assessed and expressed (e.g., Gadow et al., 2005) were evident. There were studies, however, that did not find diagnostic subgroup differences in anxiety (e.g., Kim et al., 2000). Gadow and colleagues (2005) found that both parents and teachers rated children with AS as having more severe anxiety, depression, and obsessions than children with AD. Individuals diagnosed with AS are often less severely affected, especially in terms of communication and adaptive skill delay, than are people with $\mathrm{AD}$. Thus, there may be an inverse relationship between severity of core ASD symptoms and comorbid psychiatric impairment (e.g., Gadow et al., 2005), but this relationship requires more investigation.

Given that there is emerging evidence of possible differences in psychiatric comorbidity among the ASD subtypes, future research should clearly specify ASD diagnoses of participants and confirm diagnoses with evidence-based diagnostic tools. Also, given differences in cognitive functioning usually associated with ASD subtypes, future studies should examine how diagnosis might independently be associated with anxiety. In other words, the separate effects of diagnosis and functional level on the prevalence and expression of anxiety, as well as treatment outcome, are yet to be clearly determined. Kanai and colleagues (2004), for example, controlled for group differences in IQ between children with HFA and those with PDD-NOS, and found that the children with PDD-NOS exhibited stronger anxiety reactions. Kim et al. (2000) found no differences between children with HFA and those with AS in prevalence of emotional problems, but none of the children in their sample had intellectual disabilities.

The majority of the studies reviewed used clinic-based samples (e.g., Gadow et al., 2005; Green et al., 2000) or (e.g., Pearson et al., 2006; Pfeiffer et al., 2005) samples recruited from a variety of other sources (e.g., autism support groups). In contrast, Simonoff et al. (2008) drew their ASD sample from a large population-derived, non-clinical cohort. Clinical samples are often needed to accrue an adequate number of participants and for ensuring statistical power, but such samples can make it difficult to generalize findings. For example, it is unclear if a treatment conducted with a clinically referred sample will transfer effectively to students in a school setting who are identified as having ASD. Clinic-based samples are likely not representative of all children with ASD in many important respects, such as degree of parental investment, level of behavior disturbance, and previous treatment exposure. Further studies using non-clinical, community based and school samples are needed to evaluate the prevalence of anxiety in the broader ASD population.

There are many questions about the presentation and course of anxiety in children with ASD. The developmental waxing and waning of specific forms of anxiety in ASD is not well understood. Studies that have examined symptoms of anxiety across children of different ages (e.g., Farrugia \& Hudson, 2006) have generally found that, similar to typically developing anxious youth (Ollendick, King, \& Muris, 2004), specific phobias may be more common in younger children with ASD, while disorders such as OCD and social phobia become more common during adolescence. It is quite possible that youth with ASD face considerable challenges during the transition from childhood to adolescence. Social difficulties and awareness of being different from others, especially during the teen years, may lead to problems with anxiety, depression, or hostility (Tantam, 2003). For teens with ASD, adapting to new environments and quickly changing routines at school can be overwhelming. Physical, hormonal, and socio-emotional changes compound the ever-present challenges associated with academic, family, and social expectations (Khouzam, El-Gabalawi, \& Priest, 2004). Cooccurring social skill deficits make succeeding in the complex social milieu of middle school and high school extremely difficult. More research is needed to understand developmental effects on anxiety in teens with ASD.

To understand how anxiety may change over the course of childhood and adolescence and to inform development of treatment interventions, further research is needed on possible 
etiological pathways of anxiety in ASD. There is evidence for both structural and neurochemical disturbances in youth with ASD that may predispose them to experience problems with anxiety. Serotonin levels in children with ASD may be associated with anxiety (Apter, Brown, Korn, \& van Praag, 1991). Studies using neuroimaging and behavioral data have found abnormal amygdalar structure and function in young persons with ASD, which has been hypothesized to be related to higher rates of fears and anxiety (Amaral, Bauman, \& Schumann, 2003). Juranek at al. (2006) found a relationship between amygdala volume and symptoms of anxiety and depression in children with ASD. There may also be genetic associations between anxiety and ASD. Family studies have shown higher rates of anxiety disorders, including social anxiety disorder, in first-degree relatives of individuals with $\mathrm{AD}$ in comparison to typically developing controls (Piven \& Palmer, 1999; Smalley, McCracken, \& Tanguay, 1995). The mechanisms underlying a possible genetic vulnerability to anxiety, however, remain elusive (Piven \& Palmer).

Another clinically relevant question is the degree to which anxiety in children with ASD affects the lives of their parents and other family members, as well as to what degree co-occurring anxiety problems affect prognosis for the children with ASD themselves. Kim et al. (2000), for example, found that children with AS who also had mood or anxiety problems were more aggressive and had poorer relationships with their teachers, peers, and family members, and that their parents had more limited social lives. Related to outcome and social relationships, research has not yet elucidated the connection between social difficulties, a core characteristic of all spectrum conditions, and anxiety. There may be a bi-directional influence, or one may mediate the other. Regardless, it is clear that anxiety can amplify the social impairment already present. When a child experiences stress, for example, he may retreat further into himself, spend more time engaged in ritualized or repetitive behaviors, or even become irritable and aggressive (Tantam, 2003). In essence, a feedback loop exists in which anxiety and social difficulty feed upon one another in a cyclic manner.

Although the treatment studies reviewed demonstrated promising results in terms of efficacy, none of the studies implemented treatments specifically developed for youth with ASD. Given the growing number of children and adolescents with ASD who are in need of treatment, this is an area of research that desperately requires attention. A thorough, empirically based understanding of characteristics associated with ASD, including the thinking, behaving, and emoting patterns that may underlie anxiety within ASD, is important in informing how traditional treatment approaches will need to be adapted for this population. Future research should also seek to determine the core ingredients of effective treatment, how traditional CBT strategies may need to be modified for children with ASD, and how treatment should be delivered (e.g., group versus individual therapy, degree of parent involvement). Studies also should examine potential psychosocial treatments including traditional applied behavior analytic strategies for addressing anxiety in lower functioning children with ASD. There is evidence that treatment can be effective for anxiety in intellectually disabled individuals (Jennett \& Hagopian, 2008), but little work has looked specifically at youth on the spectrum with cognitive limitations.

\section{Clinical Implications}

Problems with anxiety likely cause additional social and developmental impairment, above and beyond the impairment caused by the core difficulties associated with ASD. Current prevalence estimates indicate that almost one in 150 children is diagnosed with an ASD (United States Centers for Disease Control, 2007). Spectrum conditions are known to be life-long and many identified children will require psychiatric treatment as they progress into middle childhood, adolescence, and adulthood. The need for accurate assessment of psychiatric comorbidity and effective treatments, therefore, will continue to grow. All clinicians, including 
those who do not specialize in ASD, should expect to come into contact with individuals in need of treatment in their professional roles. There are several conclusions to draw from this review that are directly relevant to clinical practice.

First, the presentation of anxiety in youth with ASD is similar in many respects to that of nonASD youth (e.g., developmental progression of symptoms) but different in other respects (e.g., association with sensory sensitivities, lack of emotional insight). The complex expression of anxiety in teens and children with ASD may contribute to the unfortunate probability that the anxiety symptoms of some children are overlooked or mislabeled. A child with an ASD may begin acting out more at home or school, or parents may report an increase in the child's repetitive behavior or in the intensity of restricted interest(s). The symptoms and fears may not be age-typical, and the child may not be capable of reporting accurately on his or her symptoms or may deny experiencing severe worries, despite behavioral evidence to the contrary. The adolescent with ASD may lack insight into his or her internal feelings and anxious thoughts, despite being able to describe overt signs of anxiety (e.g., avoiding sitting with peers at lunch) when asked. A thorough understanding of the child's cognitive abilities and ASD severity, including communication and social impairments, should also inform diagnosis. An ideal assessment battery for anxiety in ASD would include parent-, self-, and other- report measures along with clinical interview. Such a battery would consider a wide range of possible anxiety symptoms and be efficient enough for clinical practice. In terms of the ideal informant, based on the literature, it is our contention that both parent- and teacher-reports are needed in the assessment of anxiety in young children (e.g., below age eight) and those who are more severely cognitively impacted (e.g., moderate to severe intellectual disability) with ASD. For schoolage children and adolescents who have few cognitive limitations, there should be equal if not more reliance on self-reports of anxiety symptoms by the youth themselves. In all cases, however, we strongly recommend use of reliable and valid structured diagnostic interviews and ratings scales.

Higher functioning children with ASD, in comparison to those with PDD-NOS or AD who may be lower functioning, are usually diagnosed later in childhood, when a child's social oddities and idiosyncratic, stereotyped interests and behaviors become more evident and impairing (Gillberg, 1989; Khouzam et al., 2004). The unfortunate result for many children with AS or HFA may be a missed opportunity to benefit from intensive early intervention. It is imperative that effective treatments be developed and empirically evaluated for the AS/HFA population, and that efforts continue to be made at earlier identification of all ASDs. Based on a recent review of anxiety disorders in people with developmental disabilities, including ASD, Davis and colleagues (2008) concluded that such disorders may not be identified or treated as often as they typically are in people without developmental disabilities due to poor communication skills and the presence of other symptoms.

To treat anxiety in youth with ASD, a multimodal approach that accommodates the child's learning style, unique strengths, and limitations is called for. Individuals with ASD often exhibit cognitive risk factors for developing anxiety, such as excessive self-focus (Kendall \& Ronan, 1990) and social-cognitive deficits (Bellini, 2003). Difficulty regulating stress levels and heightened levels of arousal (e.g., Loveland, 2005; Pfeiffer et al., 2005) may further increase risk for the development of comorbid anxiety problems. In addition to addressing these issues in individual therapy, interdisciplinary collaboration is essential. For example, children with sensory sensitivities or sensory-seeking behavior may require strategies based in occupational therapy (e.g., application of deep pressure) to help alleviate anxiety. Such interventions require further investigation, however. School consultation may be needed to educate the child's teachers and provide recommendations for modifying the student's classroom environment and social encounters. The teacher can facilitate a more structured lunchtime for the student in order to decrease stress. Medication may help alleviate severe 
anxiety, and may complement therapy by making the child more receptive to psychosocial treatments.

Although there is currently not an evidence-based treatment program designed specifically for anxiety reduction in youth with ASD, results from initial cognitive-behavioral treatment studies are promising (e.g., Chalfant et al., 2006; Reaven \& Hepburn, 2003; Sofronoff et al., 2005). Modifications to traditional CBT, however, will usually be necessary. Modifications may include more frequent practice and exposure opportunities, increased parent involvement to promote skill use and generalization outside of treatment, incorporating visual aids especially when teaching concepts (e.g., use of cartoons and thought bubbles to identify distorted thoughts), and making therapy sessions highly structured and predictable. Treatment outcome may be enhanced by including explicit social skills instruction and practice and teaching of strategies to decrease over-arousal. Parent education and support, including referrals to local parent support groups or agencies, can also be beneficial. As previously discussed, most of the psychosocial treatment studies have not included lower functioning children with ASD. Nonmedical treatment options for younger, lower functioning children with ASD remain to be investigated.

\section{Conclusions}

Despite the lack of firm prevalence data on the co-occurrence of anxiety disorders in youth with ASD, problems with anxiety appear more frequently in youth with ASD than in many other clinical and non-clinical populations. The presentation of anxiety is likely affected by age, level of cognitive functioning, ASD-specific difficulties (e.g., over-arousal), and degree of social impairment. Further research is needed to identify the risk factors and etiological pathways for anxiety in ASD. As the number of children identified with ASD grows, so does the need for accurate assessment tools and effective treatment approaches. The conceptualization of anxiety in patients with ASD can be complex. Clinicians often are faced with determining if an anxiety problem represents a true comorbid condition, or if the anxiety is secondary to, or reflective of, the deficits associated directly with the ASD diagnosis. There is currently no pharmacological or psychosocial treatment program for the core symptoms of ASD. However, there is emerging evidence that many associated problems, including anxiety, can be effectively managed. This review has summarized the research literature on anxiety in ASD and offered recommendations for future research and clinical implications.

Understanding and treatment of anxiety in ASD will continue to be an area in need of sophisticated research as a growing number of families seek treatment for such problems.

\section{Acknowledgments}

This project was supported by a grant from the National Institute of Mental Health [1K01MH079945-01; PI: S. W. White]

\section{References}

References marked with an asterisk indicate studies of ASD included in the review.

Achenbach, TM.; Edelbrock, CS. Manual for the Child Behavior Checklist and revised child Behavior Profile. Burlington, VT: University of Vermont Department of Psychiatry; 1983.

Albano, AM.; Silverman, WK. Anxiety Disorders Interview Schedule for DSM-IV: Child version Clinical manual. San Antonio: Psychological Corporation; 1996.

Aman MG, Tasse MJ, Rojahn J, Hammer D. The Nisonger CBRF: A child behavior rating form for children with developmental disabilities. Research in Developmental Disabilities 1996;17:41-57. [PubMed: 8750075] 
Amaral DG, Bauman MD, Schumann CM. The amygdale and autism: Implications from non-human primate studies. Genes, Brain, and Behavior 2003;2:295-302.

American Psychiatric Association. Diagnostic and statistical manual of mental disorders. Vol. 3. Washington, DC: Author; 1987.

American Psychiatric Association. Diagnostic and statistical manual of mental disorders. Vol. 4. Washington, DC: Author; 2000. text revision

Apter, A.; Brown, S-L.; Korn, ML.; van Praag, HM. Psychiatric disorders of childhood: The role of serotonin. In: Brown, S-L.; van Praag, HM., editors. Clinical and Experimental Psychiatry Monograph: No 4 The Role of Serotonin in Psychiatric Disorders. Philadelphia, PA: Brunner/Mazel; 1991. p. 215-238.

Attwood T. Strategies for improving the social integration of children with Asperger syndrome. Autism 2000;4:85-100.

Attwood T. James and the Maths Test. 2002Unpublished manuscript

Attwood T. Frameworks for behavioral interventions. Child and Adolescent Psychiatric Clinics of North America 2003;12:65-86. [PubMed: 12512399]

Beidel DC, Turner SM, Morris TL. A new inventory to assess childhood social anxiety and phobia: The social phobia and anxiety inventory for children. Psychological Assessment 1995;7:73-79.

Bellini, SC. Anxiety in individuals with autism spectrum disorders: The role of social skill deficits. Indiana University; 2003. Unpublished doctoral dissertation

* Bellini S. 2004; Social skill deficits and anxiety in high-functioning adolescents with autism spectrum disorders. Focus on Autism and Other Developmental Disabilities 19:78-86.86

* Bellini S. 2006; The development of social anxiety in adolescents with autism spectrum disorders. Focus on Autism and Other Developmental Disabilities 21:138-145.145

* Bhardwaj A, Agarwal V, Sitholey P. 2005;Asperger's disorder with co-morbid separation anxiety disorder: A case report. Journal of Autism and Developmental Disorders 35:135-136.136 [PubMed: 15796129]

* Bradley EA, Summers JA, Wood HL, Bryson SE. 2004;Comparing rates of psychiatric and behavior disorders in adolescents and young adults with severe intellectual disability with and without autism. Journal of Autism and Developmental Disorders 34:151-161.161 [PubMed: 15162934]

* Buitelaar JK, van der Gaag J, van der Hoeven J. 1998;Buspirone in the management of anxiety and irritability in children with pervasive developmental disorders: Results of an open-label study. Journal of Clinical Psychiatry 59:56-59.59 [PubMed: 9501886]

* Burnette CP, Mundy PC, Meyer JA, Sutton SK, Vaughan AE, Charak D. 2005; Weak central coherence and its relations to theory of mind and anxiety in autism. Journal of Autism and Developmental Disorders 35:63-73.73 [PubMed: 15796123]

Chakrabarti S, Fombonne E. Pervasive developmental disorders in preschool children: Confirmation of high prevalence. American Journal of Psychiatry 2005;162:1133-1141. [PubMed: 15930062]

* Chalfant A, Rapee R, Carroll L. 2006Treating anxiety disorders in children with high functioning autism spectrum disorders: A controlled trial. Journal of Autism and Developmental Disorders. Retrieved February 16, 2007, from http://dx.doi.org/101007/s10803-006-0318-4.

Conners CK. Symptom patterns in hyperkinetic, neurotic, and normal children. Child Development 1970;41:667-682.

Coolidge FL, Thede LL, Stewart SE, Segal DL. The Coolidge Personality and Neuropsychological Inventory for Children (CPNI): Preliminary psychometric characteristics. Behavior Modification 2002;26:550-566. [PubMed: 12205827]

* Couturier JL, Nicolson R. 2002;A retrospective assessment of citalopram in children and adolescents with pervasive developmental disorders. Journal of Child and Adolescent Psychopharmacology 12:243-248.248 [PubMed: 12427298]

Davis E, Saeed SA, Antonacci DJ. Anxiety disorders in persons with developmetnal disabilities: Empirically informed diagnosis and treatment. Psychiatry Quarterly 2008;79:249-263.

* de Bruin EI, Ferdinand RF, Meester S, de Nijs PF, Verheij F. 2006;High rates of psychiatric comorbidity in PDD-NOS. Journal of Autism and Developmental Disorders 37:877-886.886 [PubMed: 17031447] 
* Edelson SM, Edelson MG, Kerr DCR, Grandin T. 1999;Behavioral and physiological effects of deep pressure on children with autism: A pilot study evaluating the efficacy of Grandin's Hug Machine. American Journal of Occupational Therapy 53:145-152.152 [PubMed: 10200837]

Einfeld, SL.; Tonge, BJ. Manual for the Developmental Behaviour Checklist. Clayton: Australia: Monash University Centre for Developmental Psychiatry and School of Psychiatry, University of New South Wales; 1994.

* Evans DW, Canavera K, Kleinpeter FL, Maccubbin E, Taga K. 2005; The fears, phobias and anxieties of children with autism spectrum disorders and Down syndrome: Comparisons with developmentally and chronologically age matched children. Child Psychology and Human Development 36:3-26.26

* Farrugia S, Hudson J. 2006;Anxiety in adolescents with Asperger syndrome: Negative thoughts, behavioral problems, and life interference. Focus on Autism and Other Developmental Disabilities 21:25-35.35

Ferdinand, RF.; Van der Ende, J. Diagnostic Interview Schedule for Children IV-Parent-version. Rotterdam, Netherlands: Erasmus University, Department of Child and Adolescent Psychiatry; 1998.

Foa, EB.; Costello, EJ.; Franklin, M.; Kagan, J.; Kendall, P.; Klein, R., et al. Anxiety disorders. In: Evans, DL.; Foa, EB.; Gur, RE.; Hendin, H.; O’Brien, CP.; Seligman, MEP.; Walsh, T., editors. Treating and preventing adolescent mental health disorders: What we know and what we don't know. New York: Oxford Press; 2005.

Frith, U. Autism: Explaining the enigma. Oxford: Basil Blackwell; 1989.

* Gadow KD, Devincent CJ, Pomeroy J, Azizian A. 2005;Comparison of DSM-IV symptoms in elementary school-age children with PDD versus clinic and community samples. Autism 9:392415.415 [PubMed: 16155056]

Gadow, KD.; Sprafkin, J. Early Childhood Symptom Inventory-4 Norms Manual. Stony Brook, NY: Checkmate Plus; 1997a.

Gadow, KF.; Sprafkin, J. Adolescent symptom inventory-4 screening manual. Stony Brook, NY: Checkmate Plus; 1997b.

Gadow, KD.; Sprafkin, J. Child Symptom Inventory-4 Screening and Norms Manual. Stony Brook, NY: Checkmate Plus; 2002.

Ghaziuddin M. Asperger syndrome: Associated psychiatric and medical conditions. Focus on Autism and Other Developmental Disabilities 2002;17:138-144.

Gillberg C. Asperger syndrome in 23 Swedish children. Developmental Medicine \& Child Neurology 1989;31:520-531. [PubMed: 2680690]

* Gillott A, Furniss F, Walter A. 2001; Anxiety in high-functioning children with autism. Autism 5:277286.286 [PubMed: 11708587]

* Green J, Gilchrist A, Burton D, Cox A. 2000; Social and psychiatric functioning in adolescents with Asperger syndrome compared with conduct disorder. Journal of Autism and Developmental Disorders 30:279-293.293 [PubMed: 11039855]

Greig A, MacKay T. Asperger's Syndrome and cognitive behaviour therapy: New applications for educational psychologists. Educational \& Child Psychology 2005;22:4-15.

Guy, W. US Dept Health, Education, and Welfare publication. Rockville, MD: National Institute of Mental Health; 1976. ECDEU Assessment Manual for Psychopharmacology; p. 218-222.ADM No 76-338

Jennett HK, Hagopian LP. Identifying empirically supported treatments for phobic avoidance in individuals with intellectual disabilities. Behavior Therapy 2008;39:151-161. [PubMed: 18502248]

* Johnson SM, Hollander E. 2003;Evidence that eicosapentaenic acid is effective in treating autism. Journal of Clinical Psychiatry 64:848-849.849 [PubMed: 12934990]

* Juranek J, Filipek PA, Berenji GR, Modahl C, Osann K, Spence MA. 2006;Association between amygdala volume and anxiety level: Magnetic resonance imaging (MRI) study in autistic children. Journal of Child Neurology 21:1051-1068.1068 [PubMed: 17156697]

* Kanai C, Koyama T, Kato S, Miyamoto Y, Osada H, Kurita H. 2004;Comparison of high-functioning atypical autism and childhood autism by Childhood Autism Rating Scale-Tokyo version. Psychiatry and Clinical Neurosciences 58:217-221.221 [PubMed: 15009830]

Kanner L. Autistic disturbances of affective contact. Nervous Child 1943;2:217-250. 
* Kauffmann C, Vance H, Pumariega AJ, Miller B. 2001; Fluvoxamine treatment of a child with severe PDD : A single case study. Psychiatry: Interpersonal and Biological Processes 64:268-277.277

Kaufman J, Birmaher B, Breut D. Schedule for affective disorders and schizophrenia for school age children present and lifetime version (K-SADS-PL) : Initial reliability and validity data. Journal of the American Academy of Child and Adolescent Psychiatry 1997;36:83-93.

Kendall, P.; Ronan, K. Assessment of children's anxieties, fears, and phobias. In: Reynolds, CR.; Kamphaus, RW., editors. Handbook of Psychological and Educational Assessment of Children. New York: Guilford Press; 1990. p. 223-244.

Khouzam HR, El-Gabalawi F, Priest F. Asperger's disorder : A review of its diagnosis and treatment. Comprehensive Psychiatry 2004;45:183-191.

* Kim JA, Szatmari P, Bryson SE, Streiner DL, Wilson FJ. 2000; The prevalence of anxiety and mood problems among children with autism and Asperger syndrome. Autism 4:117-132.132

Kurita H, Miyake Y, Katsuno K. Reliability and validity of the childhood autism rating scale-Tokyo version (CARS-TV). Journal of Autism and Developmental Disorders 1989;19:389-396. [PubMed: 2793784]

LaGreca, AM. Social Anxiety Scales for Children and Adolescents manual. Miami, FL: University of Miami; 1999.

LaGreca AM, Stone WL. Social anxiety scales for children-revised: Factor structure and concurrent validity. Journal of Clinical Child Psychology 1993;22:17-27.

* Lecavalier L. 2006; Behavioral and emotional problems in young people with pervasive developmental disorders: Relative prevalence, effects of subject characteristics, and empirical classification. Journal of Autism and Developmental Disorders 36:1101-1114.1114 [PubMed: 16897387]

* Lehmkuhl HD, Storch EA, Bodfish JW, Geffken GR. 2008;Brief report: Exposure and response prevention for obsessive compulsive disorder in a 12-year-old with autism. Journal of Autism and Developmental Disorders 38:977-981.981 [PubMed: 17885801]

Leyfer OT, Folstein SE, Bacalman S, Davis NO, Dinh E, Morgan J, et al. Comorbid psychiatric disorders in children with autism: Interview development and rates of disorders. Journal of Autism and Developmental Disorders 2006;36:849-861. [PubMed: 16845581]

Lord C, Risi S, Lambrecht L, Cook EH Jr, Leventhal BL, DiLavore PC, et al. The Autism Diagnostic Observation Schedule-Generic: A standard measure of social and communication deficits associated with the spectrum of autism. Journal of Autism and Developmental Disorders 2000;30:205-223. [PubMed: 11055457]

Lord C, Rutter M, Le Couteur A. Autism Diagnostic Interview-Revised: A revised version of a diagnostic interview for caregivers of individuals with possible pervasive developmental disorders. Journal of Autism and Developmental Disorders 1994;24:659-685. [PubMed: 7814313]

Lord C, Wagner A, Rogers S, Szatmari P, Aman M, Charman T, et al. Challenges in evaluating psychosocial interventions for autistic spectrum disorders. Journal of Autism and Developmental Disorders 2005;35:695-708. [PubMed: 16496206]

Loveland, KA. Social-emotional impairment and self-regulation in autism spectrum disorders. In: Nadel, J.; Muir, D., editors. Emotional development: Recent research advances. New York: Oxford University Press; 2005. p. 365-382.

Lyneham, HJ.; Abbott, MJ.; Wignall, A.; Rapee, RM. The Cool Kids family Program - therapist manual. Sydney, Australia: Macquarie University; 2003.

March, JS. Multidimensional Anxiety Scale for Children manual. North Tonawanda, NY: Multi-Health Systems; 1999.

Matson, JL. The Diagnostic Assessment for the Severely Handicapped-Revised (DASH-II). Baton Rouge, LA: Scientific Publishers; 1995.

McDougle, CJ. Current and emerging therapeutics of autistic disorder and related pervasive developmental disorders. In: Davis, KL.; Charney, D.; Coyle, JT.; Nemeroff, C., editors. Neuropsychopharmacology - The fifth generation of progress. Philadelphia: Lippincott: Williams and Wilkins; 2002. p. 566-577.

Melfsen, S.; Florin, I.; Warnke, A. Das Sozialphobie und -angsinventar fur Kinder (SPAIK). Gottengen: Hogrefe; 2001. 
* Melfsen S, Walitza S, Warnke A. 2006; The extent of social anxiety in combination with mental disorders. European Child \& Adolescent Psychiatry 15:111-117.117 [PubMed: 16523252]

* Meyer JA, Mundy PC, Van Hecke AV, Durocher JS. 2006;Social attribution processes and comorbid psychiatric symptoms in children with Asperger syndrome. Autism 10:383-402.402 [PubMed: 16908481]

* Muris P, Steerneman P, Merckelbach H, Holdrinet I, Meesters C. 1998;Comorbid anxiety symptoms in children with pervasive developmental disorders. Journal of Anxiety Disorders 12:387-393.393 [PubMed: 9699121]

Myles B, Barnhill G, Hagiwara T, Griswold D, Simpson R. A synthesis of studies on the intellectual, academic, social/emotional and sensory characteristics of children with asperger syndrome. Education and Training in Mental Retardation and Developmental Disabilities 2001;36:304-311.

* Namerow LB, Thomas P, Bostic JQ, Prince J, Monuteaux MC. 2003; Use of citalopram in pervasive developmental disorders. Journal of Developmental \& Behavioral Pediatrics 24:104-108.108 [PubMed: 12692455]

National Institute of Mental Health. Diagnostic Interview Schedule for Children (DISC), Version 2.3. New York: New York State Psychiatric Institute, Division of Child and Adolescent Psychiatry; 1992.

Nauta MH, Scholing A, Rapee RM, Abbott M, Spence SH, Waters A. A parent-report measure of children's anxiety: Psychometric properties and comparison with child-report in a clinic and normal sample. Behaviour Research and Therapy 2004;42:813-839. [PubMed: 15149901]

Ollendick TH, King NJ. Empirically supported treatments for children with phobic and anxiety disorders: Current status. Journal of Clinical Child Psychology 1998;27:156-167. [PubMed: 9648033]

Ollendick, TH.; King, NJ.; Muris, P. Phobias in children and adolescents. In: Maj, M.; Akiskal, HS.; Lopez-Ibor, JJ.; Okasha, A., editors. Phobias. London: John Wiley \& Sons, Inc.; 2004. p. 245-279.

* Ozbayrak KR. 1997; Sertraline in PDD. Journal of the American Academy of Child \& Adolescent Psychiatry 36:7-8.8 [PubMed: 9000775]

* Pearson DA, Loveland KA, Lachar D, Lane DM, Reddoch SL, Mansour R, et al. 2006;A comparison of behavioral and emotional functioning in children and adolescents with autistic disorder and PDDNOS. Child Neuropsychology 12:321-333.333 [PubMed: 16911976]

* Pfeiffer B, Kinnealey M, Reed C, Helzberg G. 2005;Sensory modulation and affective disorders in children and adolescents with Asperger's disorder. The American Journal of Occupational Therapy 59:335-345.345 [PubMed: 15969281]

Piacentini J, Bergman L, Keller M, McCracken J. Functional impairment in children and adolescents with obsessive-compulsive disorder. Journal of Child and Adolescent Psychopharmacology 2003;13:S61-S69. [PubMed: 12880501]

Piven J, Palmer P. Psychiatric disorder and the broad autism phenotype: Evidence from a family study of multiple-incidence autism families. American Journal of Psychiatry 1999;156:557-563. [PubMed: 10200734]

* Reaven J, Hepburn S. 2003; Cognitive-behavioral treatment of obsessive-compulsive disorder in a child with Asperger syndrome: A case report. Autism 7:145-164.164 [PubMed: 12846384]

Reynolds, CR.; Kamphaus, RW. Behavioral Assessment System for Children manual. Circle Pines, MN: American Guidance Service; 1992.

Reynolds, CR.; Kamphaus, RW. Behavior Assessment System for Children. Circle Pines, MN: American Guidance Service; 1998.

* Russell E, Sofronoff K. 2005; Anxiety and social worries in children with Asperger syndrome. The Australian and New Zealand Journal of Psychiatry 39:633-638.638 [PubMed: 15996146]

Scahill L, Riddle M, McSwiggin-Hardin M, Ort SI, King RA, Goodman WK, et al. Children's YaleBrown Obsessive Compulsive Scale: Reliability and validity. Journal of the American Academy of Child \& Adolescent Psychiatry 1997;36:844-852. [PubMed: 9183141]

Schopler, E.; Reichler, R.; Renner, R. The Childhood Autism Rating Scale. Western Psychological Services; 1986.

* Silveira R, Jainer AK, Bates G. 2004;Fluoxetine treatment of selective mutism in pervasive developmental disorder. International Journal of Psychiatry in Clinical Practice 8:179-180.180 
Silverman WK, Pina AA, Viswesvaran C. Evidence-based psychosocial treatments for phobic and anxiety disorders in children and adolescents. Journal of Clinical Child and Adolescent Psychology 2008;37:105-130. [PubMed: 18444055]

* Simonoff E, Pickles A, Charman T, Chandler S, Loucas T, Baird G. 2008;Psychiatric disorders in children with autism spectrum disorders: prevalence, comorbidity, and associated factors in a population-derived sample. Journal of the American Academy of Child and Adolescent Psychiatry 47:921-929.929 [PubMed: 18645422]

Smalley S, McCracken J, Tanguay P. Autism, affective disorders, and social phobia. American Journal of Medical Genetics 1995;60(1):19-26. [PubMed: 7485230]

* Sofronoff K, Attwood T, Hinton S. 2005;A randomized controlled trial of a CBT intervention for anxiety in children with Asperger syndrome. Journal of Child Psychology and Psychiatry 46:11521160.1160 [PubMed: 16238662]

Spence, SH. Social skills training: Enhancing social competence with children and adolescents. Windsor, Canada: NFER-Nelson; 1995. The social worries questionnaire.

Spence, SH. The Spence Children's Anxiety Scale. In: Sclare, I., editor. Child Psychology Portfolio. Windsor, Canada: NFER-Nelson; 1997.

Spence SH. A measure of anxiety symptoms among children. Behaviour Research and Therapy 1998;36:545-566. [PubMed: 9648330]

Sukhodolsky DG, Scahill L, Gadow KD, Arnold LE, Aman MG, McDougle CJ, et al. Parent-rated anxiety symptoms in children with pervasive developmental disorders: Frequency and association with core autism symptoms and cognitive functioning. Journal of Abnormal Child Psychology 2008;36:117128. [PubMed: 17674186]

Tantam D. The challenge of adolescents and adults with asperger syndrome. Child Adolesc Psychiatric Clin N Am 2003;12:143-163.

* Thede LL, Coolidge FL. 2006 Psychological and neurobehavioral comparisons of children with asperger's disorder versus high-functioning autism. Journal of Autism and Developmental Disorders. [February 14, 2007]; at http://dx.doi.org/101007/s10803-006-0212-0.

* Tonge BJ, Brereton AV, Gray KM, Einfeld SL. 1999;Behavioural and emotional disturbance in highfunctioning autism and Asperger syndrome. Autism 3:117-130.130

United States Centers for Disease Control and Prevention. Prevalence of autism spectrum disorders: Autism and developmental disabilities monitoring network, (No. SS-1). Surveillance Summaries, MMWR 2007 2007;56:1-40.

Velting ON, Setzer NJ, Albano AM. Update on and advances in assessment and cognitive-behavioral treatment of anxiety disorders in children and adolescents. Professional Psychology: Research and Practice 2004;35:42-54.

* Weisbrot DM, Gadow KD, DeVincent CJ, Pomeroy J. 2005; The presentation of anxiety in children with pervasive developmental disorders. Journal of Child and Adolescent Psychopharmacology 15:477-496.496 [PubMed: 16092912]

Welch L, Sovner R. The treatment of a chronic organic mental disorder with dextromethorphan in a man with severe mental retardation. British Journal of Psychiatry 1992;161:118-120. [PubMed: 1638308]

* Williamson S, Craig J, Slinger R. 2008;Exploring the relationship between measures of self-esteem and psychological adjustment among adolescents with asperger syndrome. Autism 12:391-402.402 [PubMed: 18579646]

Wirt, RD.; Lachar, D.; Klinedinst, JK.; Seat, PD. Multidimensional description of Child personality: A manual for the Personality Inventory for Children. Los Angeles: Western Psychological Services; 1984. Rev ed.

Wolery M, Garfinkle AN. Measures in intervention research with young children who have autism. Journal of Autism and Developmental Disorders 2002;32:463-478. [PubMed: 12463520]

* Woodard C, Groden J, Goodwin M, Shanower C, Bianco J. 2005; The treatment of the behavioral sequelae of autism with dextromethorphan: A case report. Journal of Autism and Developmental Disorders 35:515-518.518 [PubMed: 16134036] 


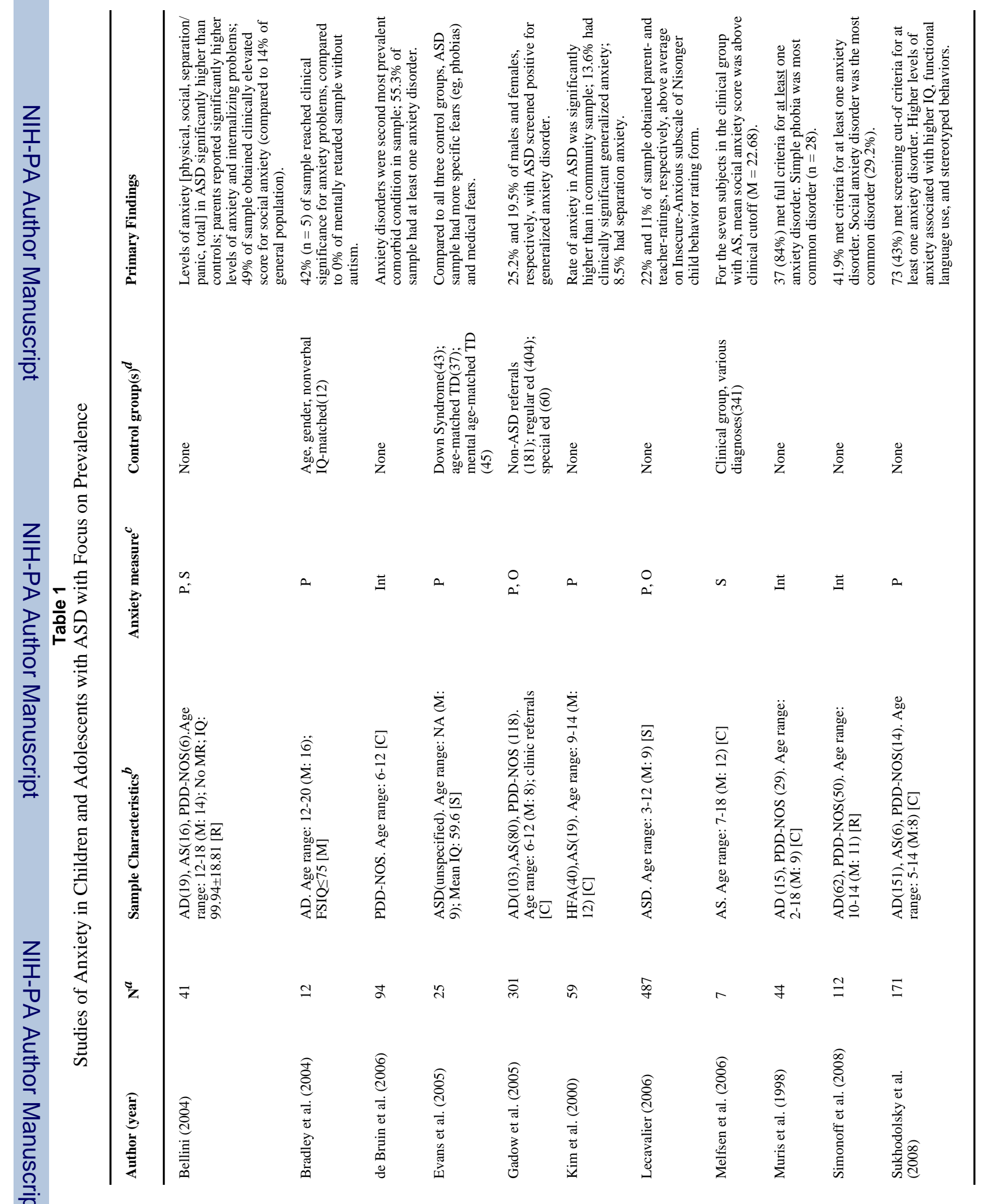




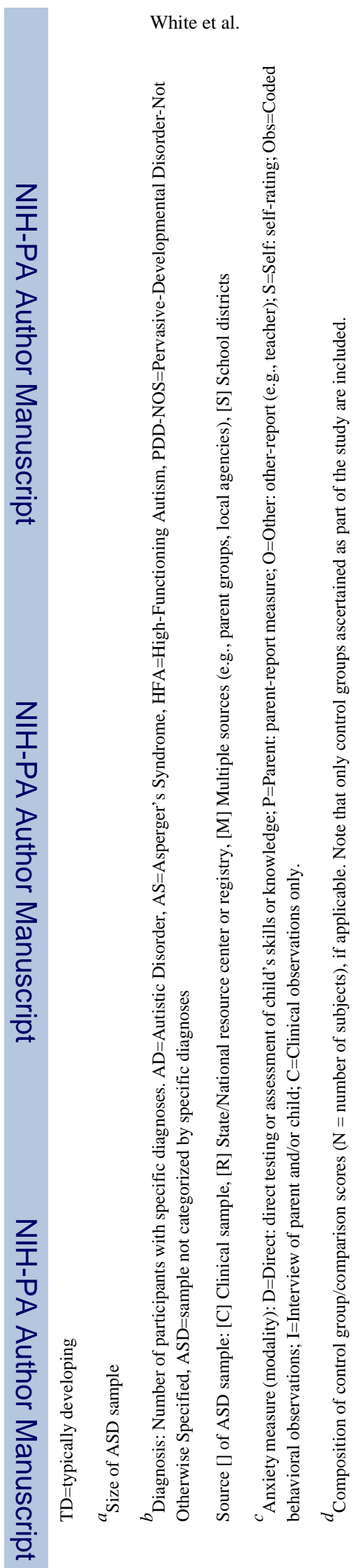

Clin Psychol Rev. Author manuscript; available in PMC 2010 April 1. 


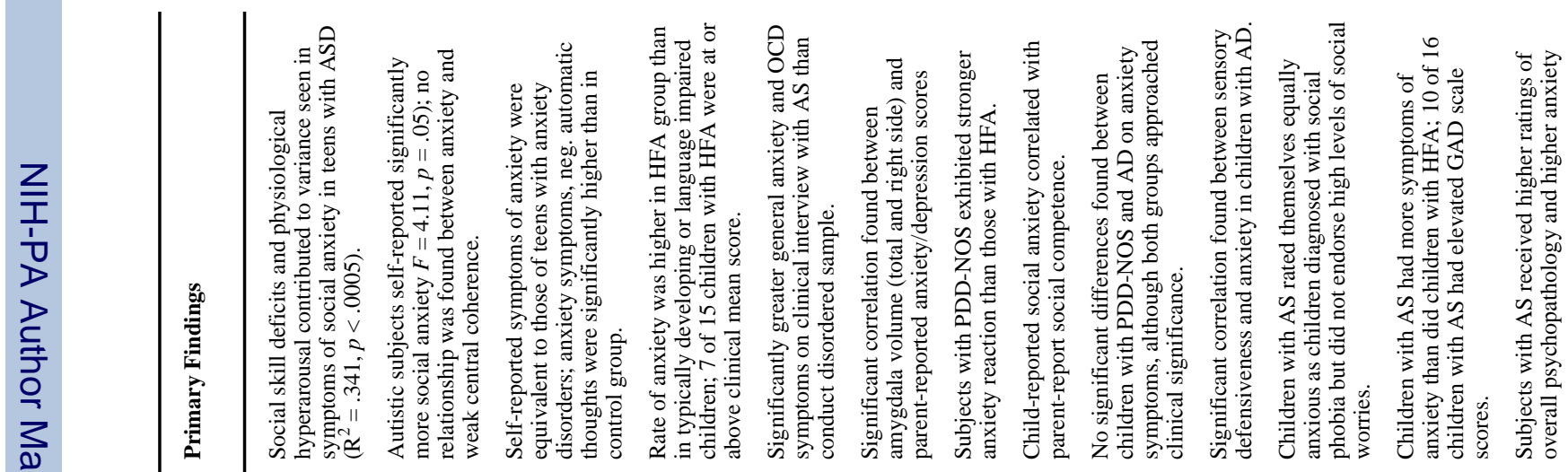
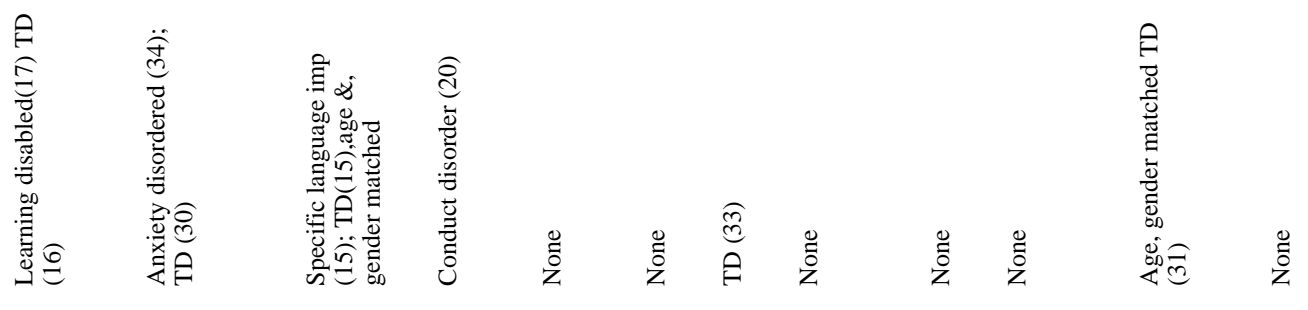

$\ddot{\Sigma}$

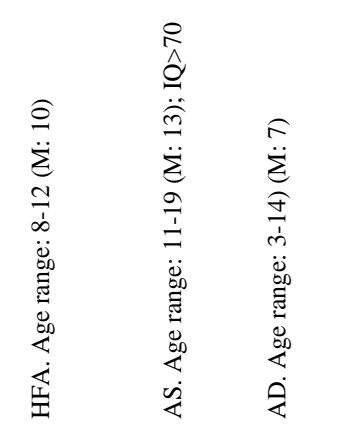

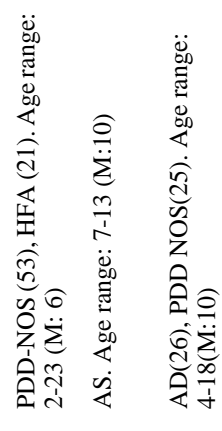

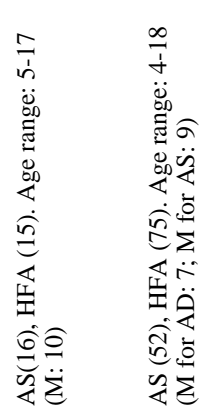

a

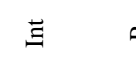
$\stackrel{n}{0}$ \& 2 $2 \quad n$

2 $\bar{m} \quad$ वे $\because$ ¿

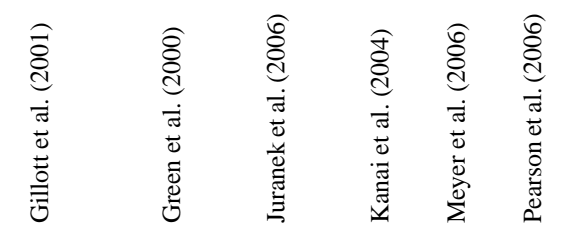

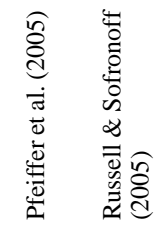

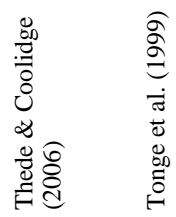


White et al.

Page 29

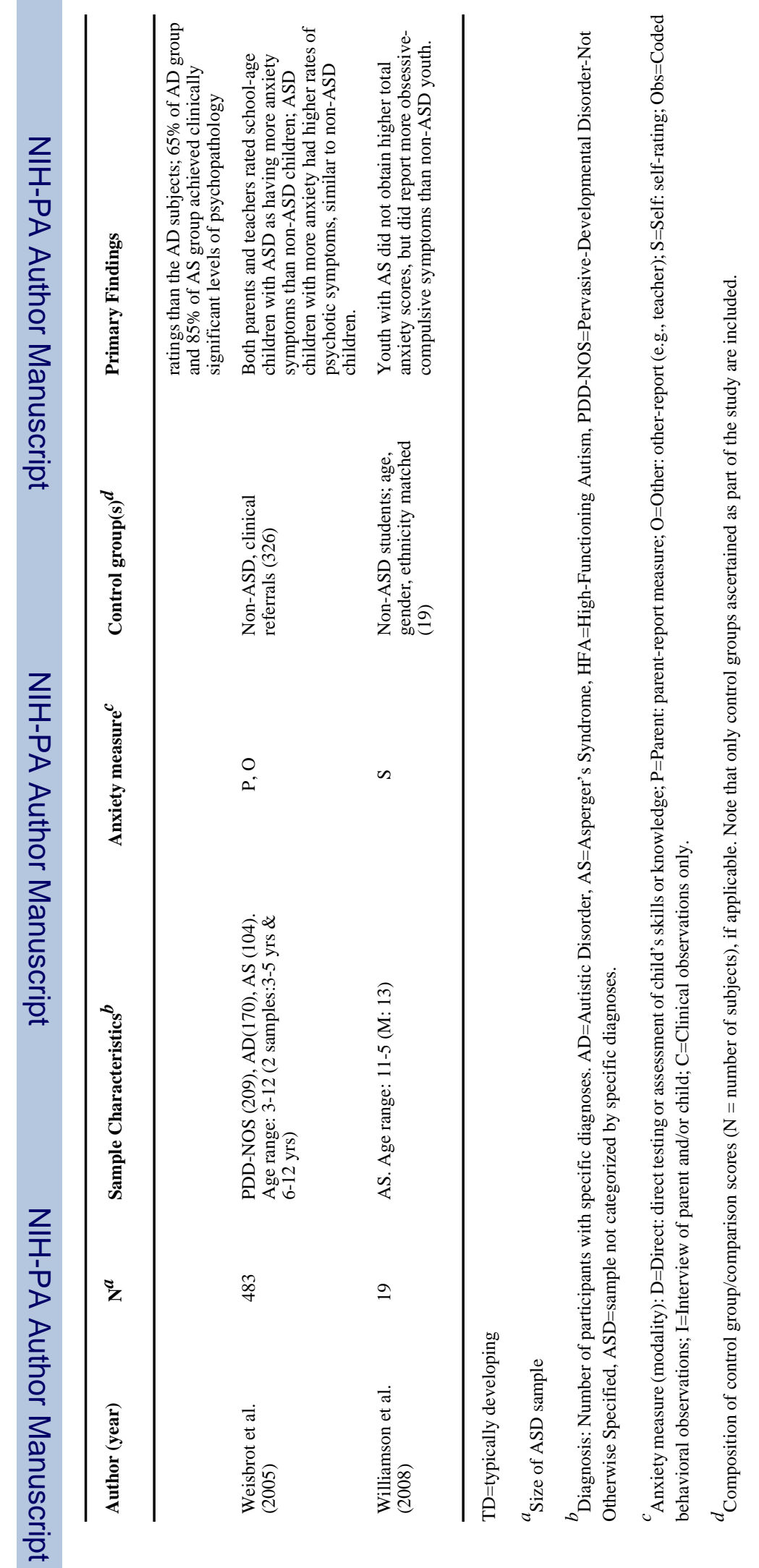

Clin Psychol Rev. Author manuscript; available in PMC 2010 April 1. 


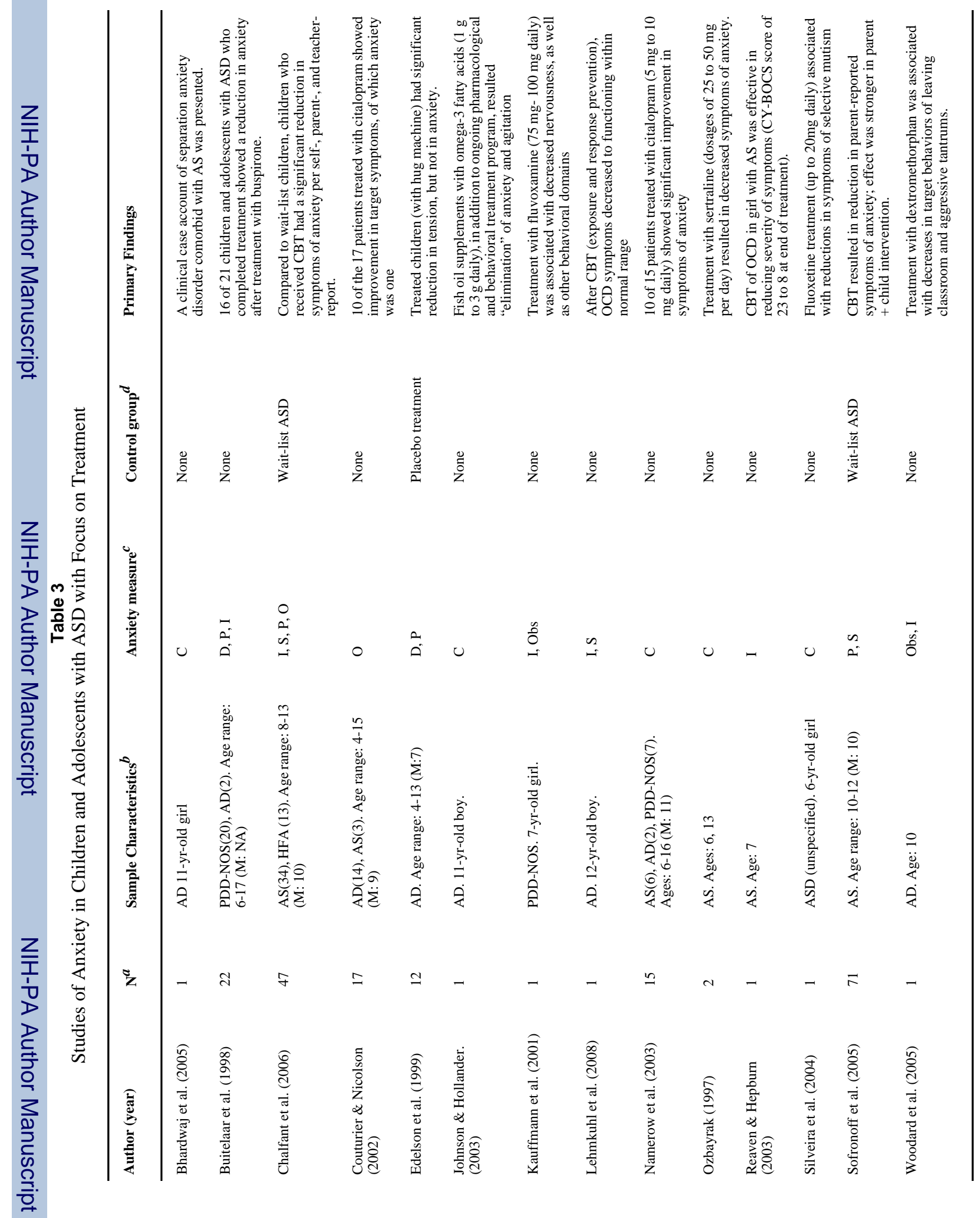




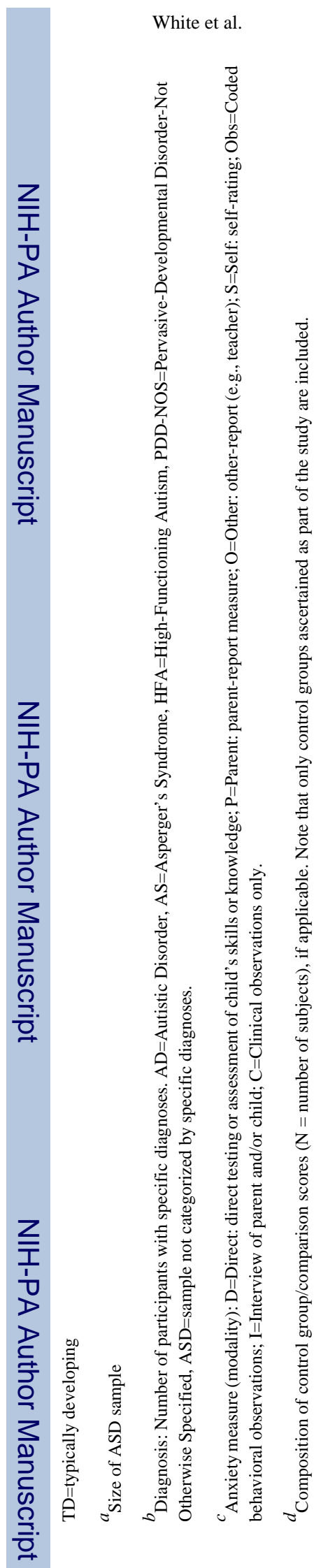

Page 31

Clin Psychol Rev. Author manuscript; available in PMC 2010 April 1. 